\title{
The Immunosuppressant Macrolide Tacrolimus Activates Cold-Sensing TRPM8 Channels
}

\author{
José Miguel Arcas, ${ }^{1}$ Alejandro González, ${ }^{1}$-Katharina Gers-Barlag, ${ }^{1}$ Omar González-González, ${ }^{1,2}$ Federico Bech, ${ }^{1,2}$ \\ Lusine Demirkhanyan, ${ }^{3}$ Eleonora Zakharian, ${ }^{3}$ Carlos Belmonte, ${ }^{1,2} \mathbb{C}^{-}$Ana Gomis, ${ }^{1}$ and ${ }^{\oplus}$ Félix Viana ${ }^{1}$ \\ ${ }^{1}$ Instituto de Neurociencias de Alicante, Universidad Miguel Hernández-CSIC, 03550 San Juan de Alicante, Spain, ${ }^{2}$ Instituto Universitario Fernández-Vega, \\ Universidad de Oviedo \& Fundación de Investigación Oftalmológica, Oviedo, Spain, and 32Department of Cancer Biology and Pharmacology, University of \\ Illinois College of Medicine, 1 Illini Drive, Peoria, Illinois 61605
}

TRPM8 is a polymodal, nonselective cation channel activated by cold temperature and cooling agents that plays a critical role in the detection of environmental cold. We found that TRPM8 is a pharmacological target of tacrolimus (FK506), a macrolide immunosuppressant with several clinical uses, including the treatment of organ rejection following transplants, treatment of atopic dermatitis, and dry eye disease. Tacrolimus is an inhibitor of the phosphatase calcineurin, an action shared with cyclosporine. Tacrolimus activates TRPM8 channels in different species, including humans, and sensitizes their response to cold temperature by inducing a leftward shift in the voltage-dependent activation curve. The effects of tacrolimus on purified TRPM8 in lipid bilayers demonstrates conclusively that it has a direct gating effect. Moreover, the lack of effect of cyclosporine rules out the canonical signaling pathway involving the phosphatase calcineurin. Menthol (TRPM8-Y745H)- and icilin (TRPM8-N799A)-insensitive mutants were also activated by tacrolimus, suggesting a different binding site. In cultured mouse DRG neurons, tacrolimus evokes an increase in intracellular calcium almost exclusively in cold-sensitive neurons, and these responses were drastically blunted in Trpm $8 \mathrm{KO}$ mice or after the application of TRPM8 antagonists. Cutaneous and corneal cold thermoreceptor endings are also activated by tacrolimus, and tacrolimus solutions trigger blinking and cold-evoked behaviors. Together, our results identify TRPM8 channels in sensory neurons as molecular targets of the immunosuppressant tacrolimus. The actions of tacrolimus on TRPM8 resemble those of menthol but likely involve interactions with other channel residues.

Key words: cornea; neuroimmune; pain; thermoreceptor; trigeminal; TRP channel

Significance Statement

TRPM8 is a polymodal TRP channel involved in cold temperature sensing, thermoregulation, and cold pain. TRPM8 is also involved in the pathophysiology of dry eye disease, and TRPM8 activation has antiallodynic and antipruritic effects, making it a prime therapeutic target in several cutaneous and neural diseases. We report the direct agonist effect of tacrolimus, a potent natural immunosuppressant with multiple clinical applications, on TRPM8 activity. This interaction represents a novel neuroimmune interface. The identification of a clinically approved drug with agonist activity on TRPM8 channels could be used experimentally to probe the function of TRPM8 in humans. Our findings may explain some of the sensory and anti-inflammatory effects described for this drug in the skin and the eye surface.

\section{Introduction}

Macrolide immunosuppressants are a class of natural compounds sharing a macrolide-like structure and potent immuno-

Received July 4, 2018; revised Nov. 2, 2018; accepted Nov. 18, 2018.

Author contributions: J.M.A., A. González, K.G.-B., E.Z., C.B., A. Gomis, and F.V. designed research; J.M.A., A. González, K.G.-B., 0.G.-G., F.B., and L.D. performed research; J.M.A., A. González, O.G.-G., F.B., L.D., and F.V. analyzed data; J.M.A. wrote the first draft of the paper; J.M.A., A. González, K.G.-B., 0.G.-G., F.B., L.D., E.Z., C.B., and A. Gomis edited the paper; F.V. wrote the paper.

This work was supported by Project SAF2016-77233-R and cofinanced by the European Regional Development Fund and the Severo Ochoa Programme for Centres of Excellence in R\&D SEV- 2013-0317. J.M.A. was supported by Spanish Ministry of Education and Science predoctoral fellowships. K.G.-B. was supported by the International PhD suppressive activity in vitro and in vivo. Tacrolimus (TAC), also known as FK506, is the best-known drug in this group. Originally isolated from the bacteria Streptomyces tsukubaensis, TAC binds
Fellowships Program La Caixa-Severo Ochoa, Call 2015. We thank Ardem Patapoutian and Ajay Dhaka for providing the Trpm $8^{\text {EGFPf }}$ mouse line; Carolina Roza, Katharina Zimmermann, and Francina Agosti for generous advice on setting up the mouse skin-nerve preparation; Salvador Sala and Jorge Fernández Trillo for help with the kinetic analysis; and Mireille Tora for excellent technical assistance.

The authors declare no competing financial interests.

Correspondence should be addressed to Félix Viana at felix.viana@umh.es.

https://doi.org/10.1523/JNEUROSCI.1726-18.2018

Copyright $\odot 2019$ the authors $\quad 0270-6474 / 19 / 390949-21 \$ 15.00 / 0$ 
to FKBP12, a protein of the immunophilin family, and this complex acts as a potent calcineurin inhibitor, a calcium/calmodulindependent Ser/Thr phosphatase. Calcineurin inhibition results in the block of T-cell activation and differentiation, thus inhibiting the release of inflammatory cytokines (for review, see Rusnak and Mertz, 2000). TAC is widely used for the prevention of transplant/graft rejection. Cyclosporine is a fungal cyclic undecapeptide, structurally unrelated to TAC but sharing similar inhibitory effects on the calcineurin pathway, and also used in preventing organ rejection. Other clinical applications of TAC include their topical use in several skin disorders, including atopic dermatitis, psoriasis, and pruritus (Beck, 2005; Stull et al., 2016), and in ophthalmology for the treatment of various diseases, including Sjögren's syndrome, allergic conjunctivitis, and dry-eye disease (DED) symptoms (Fukushima et al., 2014; Wan and Dimov, 2014).

In addition to its immunosuppressive actions, previous studies suggested possible direct effects of TAC on sensory nerve endings (Senba et al., 2004). Another study postulated the activation and subsequent desensitization of TRPV1 channels by TAC (Pereira et al., 2010). Nevertheless, the mechanisms involved in TAC effectiveness for the treatment of cutaneous disorders and DED, and its molecular targets in these tissues, are presently unclear.

Here we describe the agonistic effect of TAC, but not cyclosporine, on the cold- and menthol-activated TRPM8 channel (McKemy et al., 2002; Peier et al., 2002). This polymodal, nonselective cation channel is expressed in the soma of a subset of small-diameter primary sensory neurons and their peripheral terminals (Takashima et al., 2007; Dhaka et al., 2008). Apart from cold and cooling compounds (e.g., menthol and icilin) (McKemy et al., 2002; Bödding et al., 2007; Zakharian et al., 2010), TRPM8 is also activated by the membrane lipid phosphatidylinositol 4,5bisphosphate ( $\left.\mathrm{PIP}_{2}\right)$ (Liu and Qin, 2005; Rohács et al., 2005).

In addition to its well-established role in the activation of low-threshold thermoreceptors, responsible for the sensation of innocuous cold (Bautista et al., 2007; Dhaka et al., 2007), other studies showed the involvement of TRPM8 channels in noxious cold sensations and cold allodynia (for review, see Almaraz et al., 2014). TRPM8 channels also play a major role in the electrical activity of cold-sensitive corneal endings and have been implicated in the mechanisms of tearing and blinking (Parra et al., 2010; Robbins et al., 2012; Quallo et al., 2015), important players in the pathophysiology of DED (Belmonte et al., 2017). Other studies demonstrated the role of TRPM8 in menthol-induced analgesia during acute and inflammatory pain (Liu et al., 2013). A functional, truncated isoform of TRPM8 is expressed in endoplasmic reticulum of skin keratinocytes where it plays an important role in epidermal homeostasis (Bidaux et al., 2015). Recently, TRPM8 activation was shown to evoke intense itch relief in patients and animal models of chronic itch (Ständer et al., 2017; Palkar et al., 2018).

The involvement of TRPM8 in these and other common pathologies, including migraine, has made it a relevant therapeutic target, triggering major efforts in the identification of novel small-molecule modulators of TRPM8 channels (Moran and Szallasi, 2018). The list of selective antagonists has grown rapidly (for review, see Almaraz et al., 2014), and some have shown clinical efficacy in humans (Andrews et al., 2015). After the identification of menthol, several compounds where shown to have agonist activity on TRPM8, but most of them display cross pharmacology with other ion channels, especially with other members of the TRP family (Macpherson et al., 2006).
Here, we identified TAC, a clinically approved drug, as a TRPM8 agonist with direct gating of the channel. In addition, our characterization of TAC effects on TRPM8 mutants revealed important differences in its agonist effects compared with the canonical activator menthol, illuminating some novel aspects of TRPM8 function as a polymodal sensory receptor.

\section{Materials and Methods}

Animals. Studies were performed on young adult (1-4 months old) mice of either sex. Mice were bred at the Universidad Miguel Hernández Animal Research Facilities (ES-119-002001) and kept in a barrier facility under $12 \mathrm{~h}: 12 \mathrm{~h}$ light/dark cycle with food and water ad libitum. WT animals were of the C56Bl6/J strain. All experimental procedures were performed according to the Spanish Royal Decree 1201/2005 and the European Community Council directive 2010/63/EU, regulating the use of animals in research.

Two transgenic mouse lines were used for calcium imaging experiments and electrophysiological recordings on DRG cultures. In $\operatorname{Trpm} 8^{\mathrm{BAC}}$-EYFP mice, the fluorescent protein YFP is expressed under the Trpm 8 promoter (Morenilla-Palao et al., 2014). For experiments with $\operatorname{Trpm} 8 \mathrm{KO}$ mice, we used a transgenic knockin line, $\operatorname{Trp} m 8^{E G F P f}$, in which the Trpm 8 locus was disrupted and EGFP was inserted in frame with the Trpm8 start codon (Dhaka et al., 2007). Homozygous mice $\left(\operatorname{Trp} m 8^{E G F P f / E G F P f}\right)$ are null for TRPM8. As previously described, to enhance EGFPf expression, the lox-P-flanked neomycin selection cassette introduced into the Trpm 8 locus during the generation of the transgene was excised (Dhaka et al., 2008). Both transgenic lines allowed the identification of TRPM8-expressing cells by the expression of YFP or GFP fluorescence. Moreover, Trpm $8^{\text {EGFPf/+ }}$ (i.e., hemizygous) allowed recordings from $\operatorname{GFP}(+)$ neurons with one functional copy of TRPM8. The genotype of transgenic mice was established by PCR.

Culture and transfection of mammalian cell lines. Human embryonic kidney 293 cells (HEK293) were maintained in DMEM plus Glutamax, supplemented with $10 \% \mathrm{FBS}$ and $1 \%$ penicillin/streptomycin, incubated at $37^{\circ} \mathrm{C}$ in a $5 \% \mathrm{CO}_{2}$ atmosphere. HEK293 cells were plated in 24 -well dishes at $2 \times 10^{5}$ cells/well and transiently transfected with Lipofectamine 2000 (Thermo Fisher Scientific). When necessary, we cotransfect the cells with $1 \mu \mathrm{g}$ of TRPM8 channel plasmid (from different species) and $0.5 \mu \mathrm{g}$ of GFP plasmid. For the transfection, $2 \mu \mathrm{l}$ of Lipofectamine 2000 was mixed with the DNA in $100 \mu$ l of OptiMem (Thermo Fisher Scientific), a reduced serum media. Electrophysiological and calcium imaging recordings took place $24-36 \mathrm{~h}$ after transfection. The evening before the experiment, cells were trypsinized ( $0.25 \%$ trypsinEGTA) and reseeded at lower density in 12-mm-diameter glass coverslips previously treated with poly-L-lysine.

The expression vectors used and their source were as follows: mouse TRPM8 (NM_134252) in pcDNA5, kindly provided by Ardem Patapoutian (Scripps Research Institute), was used as a WT TRPM8. A mentholinsensitive mutant $(\mathrm{Y} 745 \mathrm{H})$ and an icilin-insensitive mutant (N799A) were obtained by site-directed mutagenesis from this WT construct as described previously (Mälkiä et al., 2009). Point mutations were confirmed by sequencing of the plasmids and posterior analysis with Lasergene software (DNASTAR). Human TRPM8 in pcDNA3 (Veit Flockerzi, Saarland University), human TRPA1 in pCMV6-AC-GFP vector (Viktorie Vlachova, Czech Academy of Sciences), mouse mycTRPM3-IRESGFP (Stefan Phillip, Saarland University), and rat TRPV1 in pcDNA3 (Davis Julius, University of California-San Francisco) were also transiently transfect in HEK293 cells using the same techniques.

HEK293 cells stably expressing rat TRPM8 channels (CR\#1 cells) (Brauchi et al., 2004) were cultured in DMEM containing 10\% of FBS, $1 \%$ penicillin/streptomycin, and $450 \mu \mathrm{g} / \mathrm{ml}$ geneticin (G418).

DRG cultures. Adult mice of either sex (1-4 months) were anesthetized with isoflurane and decapitated. The spinal cord was isolated, and DRGs were dissected out from all spinal segments and maintained in ice-cold HBSS solution. After isolation, DRGs were incubated with collagenase Type XI (Sigma-Aldrich) and dispase II for 30-45 $\mathrm{min}$ in $\mathrm{Ca}^{2+}$ - and $\mathrm{Mg}^{2+}$-free HBSS medium at $37^{\circ} \mathrm{C}$ in $5 \% \mathrm{CO}_{2}$. Thereafter, DRGs were mechanically dissociated by passing $15-20$ times through a $1 \mathrm{ml}$ pipette 
tip and filtered through a $70 \mu \mathrm{m}$ nylon filter. Neurons were harvested by centrifugation at $1200 \mathrm{rpm}$ during $5 \mathrm{~min}$. The resultant pellet was resuspended in MEM supplemented with 10\% FBS, 1\% MEM-vit, and 1\% penicillin/streptomycin and plated on poly-L-lysine-coated glass coverslips. Electrophysiological and calcium-imaging recordings were performed after $12-36 \mathrm{~h}$ in culture.

Fluorescence $\mathrm{Ca}^{2+}$ imaging. Ratiometric calcium imaging experiments were conducted with the fluorescent indicator fura-2 (Thermo Fisher Scientific). DRG neurons or HEK293 cells were incubated with $5 \mu \mathrm{M}$ fura-2 $\mathrm{AM}$ and $0.2 \%$ pluronic (Thermo Fisher Scientific) for $45 \mathrm{~min}$ at $37^{\circ} \mathrm{C}$ in standard extracellular solution. Fluorescence measurements were obtained on an inverted microscope (Leica Microsystems) fitted with an Imago-QE Sensicam camera (PCO). Fura-2 was excited at 340 and $380 \mathrm{~nm}$ (excitation time $60 \mathrm{~ms}$ ) with a rapid switching monochromator (TILL Photonics) or an LED-based system (Lambda OBC, Sutter Instruments). Mean fluorescence intensity ratios (F340/F380) were displayed online with TillVision software (TILL Photonics) every $2 \mathrm{~s}$. The standard bath solution contained the following (in mM): $140 \mathrm{NaCl}, 3$ $\mathrm{KCl}, 2.4 \mathrm{CaCl}_{2}, 1.3 \mathrm{MgCl}_{2}, 10 \mathrm{HEPES}$, and 10 glucose, and was adjusted to a pH of 7.4 with $\mathrm{NaOH}(290 \mathrm{mOsm} / \mathrm{kg})$. Calcium imaging and electrophysiological recordings were performed at a basal temperature of $33 \pm 1^{\circ} \mathrm{C}$. Before the start of the experiment, an image of the microscopic field was obtained with transmitted light and under $460 \mathrm{~nm}$ excitation wavelength, to identify fluorescent cells.

Responses to agonists were calculated by measuring the peak ratio values, after subtracting the mean baseline fluorescence ratio during the $15 \mathrm{~s}$ previous to agonist application. Responses were scored as positive if the increase in fluorescence ( $\Delta$ fura-2 ratio) was $>0.08$.

Electrophysiology in cultured cells. Whole-cell voltage- and currentclamp recordings were obtained from mice DRG neurons or transiently transfected HEK293 cells with borosilicate glass patch-pipettes (Sutter Instruments, $4-8 \mathrm{~m} \Omega$ resistance) and were performed simultaneously with temperature recordings. Signals were recorded with an Axopatch 200B patch-clamp amplifier (Molecular Devices) and digitized through a Digidata 1322A (Molecular Devices). Stimulus delivery and data acquisition were performed using pCLAMP9 software (Molecular Devices).

For neuronal recordings, we used the standard bath solution (see above) at a basal temperature of $33^{\circ} \mathrm{C}$. The intracellular solution contained the following (in $\mathrm{mm}$ ): $115 \mathrm{~K}$-gluconate, $25 \mathrm{KCl}, 9 \mathrm{NaCl}, 10$ HEPES, 0.2 EGTA, $1 \mathrm{MgCl}, 1 \mathrm{Na}_{2} \mathrm{GTP}$, and $3 \mathrm{~K}_{2} \mathrm{ATP}$, adjusted to $\mathrm{pH} 7.35$ with $\mathrm{KOH}(280 \mathrm{mOsm} / \mathrm{kg})$. In voltage-clamp recordings, amplifier gain was set at $\times 1$, sampling rate was set to $10 \mathrm{kHz}$, and the signal was filtered at $2 \mathrm{kHz}$. Neurons were voltage-clamped at a potential of $-60 \mathrm{mV}$. For current-clamp recordings, gain was set at $\times 10$, acquisition rate was 50 $\mathrm{kHz}$, and the signal was filtered at $10 \mathrm{kHz}$. Once in the whole-cell configuration, resting membrane potential was measured. In neurons that fired action potentials at rest, a small DC current was injected to bring the cell to $\sim-55 \mathrm{mV}$.

For electrophysiological experiments in HEK293 cells, to minimize desensitization of TRPM8 responses, a calcium-free extracellular solution was used (in mM as follows): $144.8 \mathrm{NaCl}, 3 \mathrm{KCl}, 1 \mathrm{EGTA}, 1.3 \mathrm{MgCl}_{2}$, 10 HEPES, and 10 glucose $(290 \mathrm{mOsm} / \mathrm{kg}, \mathrm{pH}$ adjusted to 7.4 with $\mathrm{NaOH}$ ). The intracellular solution for HEK293 recordings was (in mM as follows): $135 \mathrm{CsCl}, 2 \mathrm{MgCl}_{2}, 10$ HEPES, 1 EGTA, $5 \mathrm{Na}_{2} \mathrm{ATP}$, and 0.1 $\mathrm{NaGTP}$, adjusted to pH 7.4 with $\mathrm{CsOH}(280 \mathrm{mOsm} / \mathrm{kg})$. Recordings were performed at a basal temperature of $33 \pm 1^{\circ} \mathrm{C}$, except for the experiments in which opening and inactivation kinetics were studied in which temperature was set at $23 \pm 1^{\circ} \mathrm{C}$.

After a Giga-ohm seal was formed, and the whole-cell configuration was established, cells were voltage-clamped at a potential of $-60 \mathrm{mV}$, and voltage ramps from -100 to $150 \mathrm{mV}(0.62 \mathrm{mV} / \mathrm{ms})$ were applied at $3 \mathrm{~s}$ intervals $(0.33 \mathrm{~Hz})$. For the experiments examining the opening and inactivation kinetics, $100 \mathrm{~ms}$ duration voltage steps were applied (from -80 to $240 \mathrm{mV}$ ) from a holding potential of $-80 \mathrm{mV}$. The currents were acquired at $10 \mathrm{kHz}$, filtered at $2 \mathrm{kHz}$, The ramps were analyzed with WinASCD software package (Prof. G. Droogmans, Laboratory of Physiology, KU Leuven).

Temperature stimulation. Glass coverslip pieces with cultured cells were placed in a microchamber and continuously perfused with solu- tions warmed at $32^{\circ} \mathrm{C}-34^{\circ} \mathrm{C}$. The temperature was adjusted with a Peltier device (CoolSolutions) placed at the inlet of the chamber, and controlled by a feedback device (Reid et al., 2001). Cold sensitivity was investigated with a temperature drop to $\sim 18^{\circ} \mathrm{C}$. The bath temperature was monitored with an IT-18 T-thermocouple connected to a Physitemp BAT-12 microprobe thermometer (Physitemp Instruments) and digitized with an Axon Digidata 1322A AD converter running Clampex 9 software (Molecular Devices).

Preparation and purification of the TRPM8 protein from HEK293 cells. HEK293 cells stably expressing rat myc-tagged TRPM8 were grown to $70 \%-80 \%$ confluence, washed, and collected with PBS. Cells were harvested and resuspended in NCB buffer, containing $500 \mathrm{~mm} \mathrm{NaCl}, 50 \mathrm{~mm}$ $\mathrm{NaH}_{2} \mathrm{PO}_{4}, 20 \mathrm{~mm}$ HEPES, $10 \%$ glycerol, $\mathrm{pH} 7.5$, with addition of $1 \mathrm{~mm}$ of protease-inhibitor PMSF, $5 \mathrm{~mm} \beta$-mercaptoethanol. Thereafter, cells were lysed by the freeze-thawing method and centrifuged at low speed to remove cell debris and DNA. The supernatant was further centrifuged at $40,000 \times g$ for $2.5 \mathrm{~h}$, and the pellet resuspended in NCB buffer with addition of a protease inhibitor mixture (Roche Diagnostics), $0.1 \%$ Nonidet P40 (Roche Diagnostics), and 0.5\% dodecyl-maltoside (DDM) (Calbiochem). The suspension was incubated overnight at $4^{\circ} \mathrm{C}$ on a shaker with gentle agitation and then centrifuged for $1 \mathrm{~h}$. at 40,000 $\times$ g. Further, the TRPM8 protein was purified by immunoprecipitation with antiMyc-IgG conjugated to A/G-protein magnetic beads (Thermo Fisher Scientific), following the procedure provided by the manufacturer. All steps of purification were performed at $4^{\circ} \mathrm{C}$. For the planar lipid bilayers experiments, the protein was eluted with NCB-elution buffer, containing $0.03 \%$ lauryl maltose neopentyl glycol (LMNG) and Myc-peptide $(150 \mu \mathrm{g} / \mathrm{ml})$.

Planar lipid bilayer measurements. Planar lipid bilayers measurements were performed as previously described (Zakharian et al., 2010; Asuthkar et al., 2015). Planar lipid bilayers were formed from a solution of synthetic 1-palmitoyl-2-oleoyl-glycero-3-phosphocholine and 1-palmitoyl2-oleoyl-glycero-3-phosphoethanolaminein (Avanti Polar Lipids) in a 3:1 ratio in n-decane (Sigma-Aldrich). The solution was used to paint a bilayer in an aperture of $\sim 150 \mu \mathrm{m}$ diameter in a Delrin cup (Warner Instruments) between symmetric aqueous bathing solutions of $150 \mathrm{~mm}$ $\mathrm{KCl}, 0.2 \mathrm{mM} \mathrm{MgCl}_{2}, 1 \mu \mathrm{M} \mathrm{CaCl}_{2}, 20 \mathrm{~mm}$ HEPES, pH 7.4, at $22^{\circ} \mathrm{C}$. All lipid bilayer experiments were performed in the presence of $\mathrm{PIP}_{2}$, unless specifically omitted as indicated: $2.5 \mu \mathrm{M}$ DiC8-PIP 2 (Cayman Chemical) dissolved in water was added to both compartments. All salts were ultrapure (>99\%) (Sigma-Aldrich). Bilayer capacitances were in the range of 50-75 pF. After the bilayers had been formed, the TRPM8 protein from the micellar suspension $(20 \mathrm{ng} / \mathrm{ml})$ was added by painting to both compartments. Unitary currents were recorded with an integrating patchclamp amplifier (Axopatch 200B, Molecular Devices). The trans solution (voltage command side) was connected to the CV 201A head stage input, and the cis-solution was held at virtual ground via a pair of matched $\mathrm{Ag}-\mathrm{AgCl}$ electrodes. Currents through the voltage-clamped bilayers (background conductance $<1 \mathrm{pS}$ ) were filtered at the amplifier output (low pass, $-3 \mathrm{~dB}$ at $10 \mathrm{kHz}, 8$-pole Bessel response). Data were secondarily filtered at $100 \mathrm{~Hz}$ through an 8-pole Bessel filter (950 TAF, Frequency Devices) and digitized at $1 \mathrm{kHz}$ using an analog-to-digital converter (Digidata 1322A, Molecular Devices), controlled by pClamp10.3 software (Molecular Devices). Single-channel conductance events, all points' histograms, open probability, and other parameters were identified and analyzed using the Clampfit 10.3 software (Molecular Devices).

Isolated skin nerve preparation. Extracellular recordings from single cutaneous primary afferent axons in an isolated mouse skin-saphenous nerve preparation were obtained following previously published procedures (Roza et al., 2006; Zimmermann et al., 2009). In brief, adult male C57BL/6J mice were killed by cervical dislocation, and the hairy skin from either hindpaw, with the saphenous nerve attached, was dissected free from underlying muscles and placed in a custom made Teflon recording chamber with the corium side up (Zimmermann et al., 2009).

The chamber containing the preparation was continuously superfused at a rate of $4 \mathrm{ml} / \mathrm{min}$ with oxygenated external solution consisting of the following (in $\mathrm{mm}$ ): $107.8 \mathrm{NaCl}, 26.2 \mathrm{NaHCO}_{3}, 9.64$ sodium gluconate, 7.6 sucrose, 5.55 glucose, $3.5 \mathrm{KCl}, 1.67 \mathrm{NaH}_{2} \mathrm{PO}_{4}, 1.53 \mathrm{CaCl}_{2}$, and 0.69 
$\mathrm{MgSO}_{4}$, which was adjusted to $\mathrm{pH} 7.4$ by continuously gassing with $95 \%$ oxygen $/ 5 \% \mathrm{CO}_{2}$. Temperature of the solution was maintained $\sim 34^{\circ} \mathrm{C}$ with a SC-20 in-line heater/cooler system, driven by a CL-100 bipolar temperature controller (Warner Instruments).

After pulling back the perineurum with Dumont \#5SF forceps, a small bundle of fibers was aspirated into a patch-pipette connected to a high gain AC differential amplifier (model DAM 80; World Precision Instruments). A reference electrode was positioned inside the chamber. Input signals were amplified, digitized (CED Micro1401-3; Cambridge Electronic Design) at $25 \mathrm{kHz}$ and stored in the hard drive of a PC for off-line analysis. For recording and off-line analysis, the Spike 2 software package was used (Cambridge Electronic Design).

A small, cone-shaped piece of frozen external solution was moved slowly over the corium side of the skin and used to identify cold spots: brisk thermoreceptor fiber activity was evoked by the ice cone when in the immediate vicinity of the receptive field, and this activity stopped shortly after removing the stimulus. Cold spots identified in this way where then isolated from the surrounding tissue with a small ABS thermoplastic ring, and delivery of the subsequent cold and chemical stimuli was restricted to a circular area $(5 \mathrm{~mm}$ diameter) of the skin. Cold stimuli were performed with solutions flowing through a Peltier system customdesigned to deliver a small volume of solution inside the ring isolating the skin area. Starting from a baseline temperature of $34^{\circ} \mathrm{C}-35^{\circ} \mathrm{C}$, the temperature reached $\sim 12^{\circ} \mathrm{C}$ in $\sim 50 \mathrm{~s}$.

In control conditions, at the baseline temperature of $34^{\circ} \mathrm{C}-35^{\circ} \mathrm{C}$, cold thermoreceptors were silent, firing action potentials during the cooling ramp. The cold threshold was defined as the temperature corresponding to the first spike during a cooling ramp. When chemical sensitization led to the appearance of ongoing activity already at basal temperature, cold threshold was taken as the mean temperature during the $60 \mathrm{~s}$ preceding the start of the cooling ramp. Chemical sensitivity of single fibers was tested with consecutive applications of TAC $(30 \mu \mathrm{M})$, followed by menthol $(50 \mu \mathrm{M})$ after a period of wash. Chemical sensitivity during recordings at $34^{\circ} \mathrm{C}$ was defined as the presence of at least 20 spikes during a period of $2 \mathrm{~min}$ before the cooling ramp. To explore their effects on cold sensitivity, a cold temperature ramp was also applied in the presence of TAC or menthol.

Extracellular recording of corneal nerve terminals. Adult C57BL/6J mice (3-6 months old; $n=10$ ) were killed by cervical dislocation, their eyes extracted, mounted in a small chamber, and continuously perfused with an oxygenated solution $(\sim 310 \mathrm{mOsm} / \mathrm{kg})$ of the following composition (in mM): $128 \mathrm{NaCl}, 5 \mathrm{KCl}, 1 \mathrm{NaH}_{2} \mathrm{PO}_{4}, 26 \mathrm{NaHCO}_{3}, 2.4 \mathrm{CaCl}_{2}, 1.3$ $\mathrm{MgCl}_{2}$, and $10 \mathrm{D}$-glucose. The solution was bubbled with carbogen gas $\left(5 \% \mathrm{CO}_{2}\right.$ and $\left.95 \% \mathrm{O}_{2}\right)$ and maintained at the desired temperature with a Peltier device.

A broken patch-pipette, mounted on a micromanipulator and connected to a high-gain amplifier (Neurolog NL104, Digitimer), was gently pressed against the corneal surface to obtain extracellular recordings of single cold-sensitive corneal nerve terminals in vitro, as described previously (Parra et al., 2010; González-González et al., 2017). Recordings were digitized at $10 \mathrm{kHz}$ and stored in a computer using a CED micro 1401 interface and Spike 2 software (both from Cambridge Electronic Design).

The corneal surface was systematically explored with the recording microelectrode until the isolation of spontaneous activity. Starting from a basal temperature of $34^{\circ} \mathrm{C}$, the bath temperature was lowered in a staircase fashion to $30^{\circ} \mathrm{C}$ and $25^{\circ} \mathrm{C}$ and maintained at each level for $\sim 3$ min. After returning to $34^{\circ} \mathrm{C}$, the eye was bathed in $30 \mu \mathrm{M}$ TAC and the staircase of low temperatures repeated. Each cornea was only exposed once to the drug.

Behavioral assessment of temperature sensitivity. Male C57BL/6J mice (2-3 months old) were obtained from The Jackson Laboratory and bred in house. The TRPM8 KO line was the same used in the cellular studies and kept on a C57BL/6J background (Dhaka et al., 2007). Mice were housed in large cages (1290D Eurostandard Type III) with food and water ad libitum. Animals were tested between 8:30 A.M. and 11:00 A.M. Before testing, animals were acclimatized to handling and being held in a lightly restrained position for $30 \mathrm{~s}$ on a flat surface at room temperature. For baseline measurements, each hindpaw was placed individually in contact with the surface of a Peltier-regulated metal plate (Bioseb cold/ hot plate) set to $10^{\circ} \mathrm{C}$, and the withdrawal latency was measured with a cutoff time of $30 \mathrm{~s}$ (Menéndez et al., 2002). The mean of the two paws was calculated and taken as the baseline (i.e., naive) value for each mouse. Thereafter, each mouse received vehicle ( $8 \%$ ethanol, $2 \%$ Cremophor in saline) in one of their paws and either menthol (1\%) or TAC $(1 \%)$ in the other one. Solutions were injected intraplantarly in a volume of $25 \mu \mathrm{l}$. Animals were returned to their cages, and each paw was tested again 20 min after injections. In TRPM8 KO mice, the experiments were identical, except that menthol was not injected in these animals. In all cases, the experimenter was blind to the treatment when doing the measurements.

Behavioral assessment of blinking. Adult male C57BL/6J or Trpm $8^{-1-}$ (Dhaka et al., 2008) mice were lightly restrained, and $5 \mu \mathrm{l}$ of saline, vehicle ( $8 \%$ ethanol, $2 \%$ Cremophor in saline), TAC (1\%), or an hyperosmolar $(785 \mathrm{mOsm} / \mathrm{kg})$ solution of saline supplemented with $\mathrm{NaCl}$ was applied to one eye from the tip of a graduated micropipette (Gilson Pipetman P20). The blinking of that particular eye was recorded using a Logitech HD webcam camera at 30 frames per second. The solutions were then removed and the mice returned to their home cages and left undisturbed for at least $5 \mathrm{~h}$ between each experiment. Each animal was tested in morning and afternoon sessions, alternating the left and right eyes. Recordings were replayed at slow motion on a computer screen, and the number of blinks was counted over a 2 min period. Counting started $3 \mathrm{~s}$ after the application, as there were always some blinks associated with the application of the drop. Quantification of the number of blinks was performed independently by 2 observers on 100 videos. The correlation coefficient $(r)$ for both measurements was 0.996 .

Behavioral assessment of tearing. Adult male C57BL/6J mice $(n=10)$ were anesthetized by intraperitoneal injection of a mixture of ketamine hydrochloride ( $80 \mathrm{mg} / \mathrm{kg}$, Imalgene 1000; Merial Laboratorios) and xylazine hydrochloride (5 mg/kg, Rompun; Bayer Hispania). Basal tear flow was measured in both eyes, after consecutive applications of a drop ( $2 \mu \mathrm{l}$ ), using a graduated micropipette (Gilson Pipetman P2), of either saline, vehicle ( $8 \%$ ethanol, $2 \%$ Cremophor in saline), and TAC (1\%), in this order, using phenol red threads (Zone-Quick, Menicon Pharma). Each solution was applied for $2 \mathrm{~min}$. Thereafter, excess fluid was removed using a sterile absorbent swap (Sugi Eyespear pointed tip, Kettencach). After a rest period of $5 \mathrm{~min}$, a phenol red thread was gently placed between the lower lid and the bulbar conjunctiva at the nasal angle during $1 \mathrm{~min}$. To quantify the staining of the threads, the wetted length was measured under a stereomicroscope. After 2 additional minutes, a new solution was applied. One week later, the protocol was repeated in some of the same animals $(n=5)$ but applying saline solution in the three consecutive tests.

Chemicals. TAC, also known as FK506 (LC Laboratories) was prepared in a DMSO stock $(50 \mathrm{~mm})$ and was dissolved in prewarmed $\left(50^{\circ} \mathrm{C}\right)$ control solution. When TAC was added to the external solution, a white cloud of precipitation appeared and gentle shaking was applied until total dissolution was obtained. Due to its poor solubility in water, a solution of $30 \mu \mathrm{M}$ TAC was the highest concentration tested. The stock of cyclosporine (LC Laboratories) was also $50 \mathrm{~mm}$ in DMSO. Menthol (Scharlau), BCTC (4-(3-chloro-2-pyridinyl)-N-[4-(1,1dimethylethyl)phenyl]-1-piperazinecarboxamide; Tocris Bioscience), AMTB ( $N$-(3-aminopropyl)-2-[(3-methylphenyl)methoxy]- $N$-(2-thienylmethyl)benzamide hydrochloride; Tocris Bioscience), M8-B ( $N$-(2-aminoethyl)- $N$-[ [3-methoxy-4-(phenylmethoxy)phenyl] methyl]-2-thiophenecarboxamide hydrochloride), pregnenolone sulfate (Tocris Bioscience), allyl isocyanate (AITC; Sigma-Aldrich), and capsaicin (8-methyl- $N$-vanillyl-trans-6-nonenamide; SigmaAldrich) were prepared as stocks and stored at $-20^{\circ} \mathrm{C}$. For in vivo experiments, a $10 \%(100 \mathrm{mg} / \mathrm{ml})$ stock of TAC was prepared in $80 \%$ ethanol, 20\% Cremophor in PEG-60 Hydrogenated Castor Oil (BASF), and diluted to $1 \%$ in saline on the day of the experiment. The final solution had a homogeneous milky white color without precipitations.

Experimental design and statistical analysis. To estimate shifts in the voltage dependence of TRPM8 activation, current-voltage $(I-V)$ relationships obtained from repetitive $(0.33 \mathrm{~Hz})$ voltage ramps $(-100$ to 150 
$\mathrm{mV}, 400 \mathrm{~ms}$ duration) were fitted with a function that combines a linear conductance multiplied by a Boltzmann activation term as follows:

$$
\mathrm{I}=\mathrm{G} \times\left(\mathrm{V}-\mathrm{E}_{\mathrm{rev}}\right) /\left(1+\exp \left(\left(\mathrm{V}_{1 / 2}-\mathrm{V}\right) / \mathrm{dx}\right)\right)
$$

where $\mathrm{G}$ is the whole-cell conductance, $\mathrm{E}_{\mathrm{rev}}$ is the reversal potential of the current, $V_{1 / 2}$ is the potential for half-maximal activation, and $\mathrm{dx}$ is the slope factor. The $G$ value obtained for a high menthol concentration $(800$ $\mu \mathrm{M}$ ) was taken as $G_{\max }$ and was used for the representation of $G / G_{\max }$ curves.

For the fitting of $\mathrm{G} / \mathrm{G}_{\max }$ curves extracted from the voltage pulses protocol, a Boltzmann equation was used as follows:

$$
\mathrm{G} / \mathrm{G}_{\max }=\mathrm{A} 2+(\mathrm{A} 1-\mathrm{A} 2) /\left(1+\exp \left(\left(\mathrm{V}_{\mathrm{m}}-\mathrm{V}_{1 / 2}\right) / \mathrm{dx}\right)\right)
$$

where $\mathrm{A} 2$ is the maximal normalized conductance, $\mathrm{A} 1$ is the minimal normalized conductance, $V_{\mathrm{m}}$ is the test potential, $V_{1 / 2}$ is the potential for half-maximal activation and $\mathrm{dx}$ is the slope factor.

Conductance-voltage $(G-V)$ curves were constructed from the $I-V$ curves of individual cells by dividing the evoked current by the driving force, according to the following equation:

$$
\mathrm{G}=\mathrm{I} /\left(\mathrm{V}_{\mathrm{m}}-\mathrm{V}_{\text {rev }}\right)
$$

where $V_{\mathrm{m}}$ is the testing potential and $V_{\text {rev }}$ is the reversal potential of the current.

The threshold temperatures were estimated as the first point at which the measured signal (F340/F380 or current) deviated by at least 4 times the SD of its baseline. All fittings were performed with the LevenbergMarquardt method implemented in the Origin 8.0 software. Data are reported as mean \pm SEM. When comparing two means, statistical significance $(p<0.05)$ was assessed by Student's two-tailed $t$ test. For multiple comparisons of means, one-way ANOVAs were performed, followed by Bonferroni's post hoc analysis, using Prism version 4.00 for Windows (GraphPad Software).

\section{Results}

\section{TAC activates recombinant TRPM8 channels}

To evaluate the agonist effect of TAC on TRPM8, we performed intracellular $\mathrm{Ca}^{2+}$ imaging experiments on HEK293 cells stably expressing rat TRPM8 channels. As shown in Figure $1 A, B$, TAC produced a dose-dependent activation of TRPM8, with an estimated $\mathrm{EC}_{50}$ of $14.1 \pm 25.9 \mu \mathrm{M}(n=105$ cells $)$. Due to its poor solubility in aqueous solutions, it was not possible to test TAC at higher concentrations. At low concentrations, the calcium response evoked by TAC was sustained, whereas at higher concentrations there was some desensitization during agonist application, similar to the results observed with other chemical agonists of TRPM8 (e.g., menthol) (Rohács et al., 2005). No changes in $\mathrm{Ca}^{2+}$ levels were observed when TAC was applied in the absence of external $\mathrm{Ca}^{2+}$ (data not shown), indicating that $\mathrm{Ca}^{2+}$ influx rather than $\mathrm{Ca}^{2+}$ release is responsible for TACinduced elevation in cytosolic $\mathrm{Ca}^{2+}$.

TRPM8 is activated by cold temperature (McKemy et al., 2002; Peier et al., 2002), and menthol potentiates responses to cold (Voets et al., 2004; Mälkiä et al., 2007). Similarly, TAC produced a dose-dependent potentiation of cold-evoked responses in mouse TRPM8, with effects evident at $1 \mu \mathrm{M}$ and saturation at $\sim 10 \mu \mathrm{M}$ (Fig. 1C,D). At $10 \mu \mathrm{M}$, peak amplitude of cold-evoked responses increased approximately fourfold with respect to responses in control $(p<0.005)$ (Fig. 1D). A closer inspection of TRPM8-evoked $\left[\mathrm{Ca}^{2+}\right]_{i}$ responses during cooling pulses revealed that TAC, at concentrations of $10-30 \mu \mathrm{M}$, produced a marked shift in the threshold for cold-evoked responses toward warmer temperatures. The average shift was $\sim 7^{\circ} \mathrm{C}$ for the highest concentration tested, changing from $21.9 \pm 0.9^{\circ} \mathrm{C}$ in control solution to $29.1 \pm 0.5^{\circ} \mathrm{C}$ in $30 \mu \mathrm{M}$ TAC $(n=15, p<0.005)$.
We also explored the sensitivity of human TRPM8 to TAC. As shown in Figure 1E, TAC $(30 \mu \mathrm{M})$ produced $\left[\mathrm{Ca}^{2+}\right]_{i}$ elevations in HEK293 cells transiently expressing hTRPM8, and this activation was not observed in untransfected cells (Fig. 1E). A summary of the effects of TAC, menthol, and cold on hTRPM8 is shown in Figure $1 F$.

In contrast to the effects of TAC, cyclosporine $(30 \mu \mathrm{M})$, a structurally unrelated calcineurin inhibitor, had no effect on HEK293 cells stably expressing rat TRPM8 channels (Fig. 1G,H).

Together, these results indicate that the immunosuppressant TAC acts like a potent cold-mimetic compound on TRPM8 channels of different mammalian species by a mechanism independent of its canonical signaling pathway.

\section{TAC activates TRPM8 currents}

In whole-cell patch-clamp recordings, application of $30 \mu \mathrm{M}$ TAC activated robust whole-cell currents in HEK293 cells expressing mouse TRPM8 (Fig. 2A). The $I-V$ relationship of the TACactivated current showed strong outward rectification and a reversal potential close to $0 \mathrm{mV}$, in line with the previously described properties of TRPM8 (Fig. 2B) (Voets et al., 2004; Mälkiä et al., 2007). Confirming the results obtained in calcium imaging experiments, cold-evoked inward and outward currents were strongly potentiated in the presence of TAC (Fig. 2A,B), leading to large inward $(-8.3 \pm 1.7 \mathrm{pA} / \mathrm{pF}$ cold vs $-101.2 \pm 30.9$ $\mathrm{pA} / \mathrm{pF}$ TAC plus cold) and outward currents $(437 \pm 47 \mathrm{pA} / \mathrm{pF}$ cold vs $597 \pm 59 \mathrm{pA} / \mathrm{pF}$ TAC plus cold) $(n=7, p<0.01)$ (Fig. $2 C)$. Similar results were observed in HEK293 cells transfected with human TRPM8. In cells expressing hTRPM8, TAC (30 $\mu \mathrm{M})$ activated a rectifying nonselective current, and cold-evoked currents were strongly potentiated by TAC: $-78.7 \pm 13.4 \mathrm{pA} / \mathrm{pF}$ versus $-121.9 \pm 18.3 \mathrm{pA} / \mathrm{pF}$ at $-100 \mathrm{mV}(n=8, p<0.0001)$ and $493 \pm 26.2 \mathrm{pA} / \mathrm{pF}$ versus $594.3 \pm 55.5 \mathrm{pA} / \mathrm{pF}$ at $100 \mathrm{mV}(n=8$, $p=0.0159)$.

To confirm the agonism of TAC on TRPM8 channels, we tested the effect of AMTB, a selective TRPM8 antagonist. As shown in Figure 2D, the responses to TAC were fully suppressed by $10 \mu \mathrm{M}$ AMTB $(352 \pm 55 \mathrm{pA} / \mathrm{pF}$ in TAC vs $16 \pm 3 \mathrm{pA} / \mathrm{pF}$ in TAC plus AMTB $)(n=6, p<0.01)$. AMTB also reduced the voltage-dependent activation of TRPM8 at the baseline temperature of $33^{\circ} \mathrm{C}$. During combined application of cooling and TAC, the blocking effect of AMTB was only partial (Fig. 2D-F).

Biophysical characterization of TAC effects on TRPM8 gating Previous studies showed that low temperature and menthol activate TRPM8 channels by producing a shift in the voltage dependence of activation toward more negative potentials (Brauchi et al., 2004; Voets et al., 2004), whereas antagonists have the opposite effect (Mälkiä et al., 2007). Recently, Janssens et al. (2016) applied kinetic analysis to describe the mechanisms whereby chemical ligands impact on TRPM8 channel gating, and differentiated between two types of agonists: those stabilizing the open channel (e.g., menthol) and those that cause a destabilization of the closed state (e.g., AITC). We used mouse TRPM8 heterologously expressed in HEK293 to characterize the effects of TAC $(30 \mu \mathrm{M})$ on voltage dependence and channel gating and compared the effects of TAC, menthol, and AITC. Whole-cell recordings during steps from -80 to $240 \mathrm{mV}$ were obtained at room temperature $\left(23 \pm 1^{\circ} \mathrm{C}\right)$, leading to substantial baseline activation of TRPM8. Menthol was applied at $10 \mu \mathrm{M}$, TAC at $30 \mu \mathrm{M}$, and AITC at $10 \mathrm{mM}$, concentrations that gave rise to similar steady-state TRPM8 current amplitudes. Following the sequential application of the three agonists, the voltage protocol was 
A

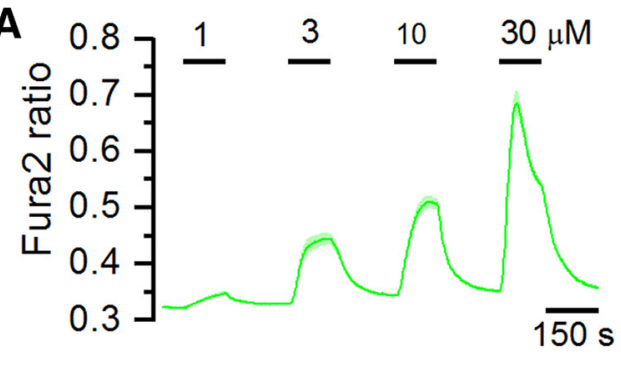

C

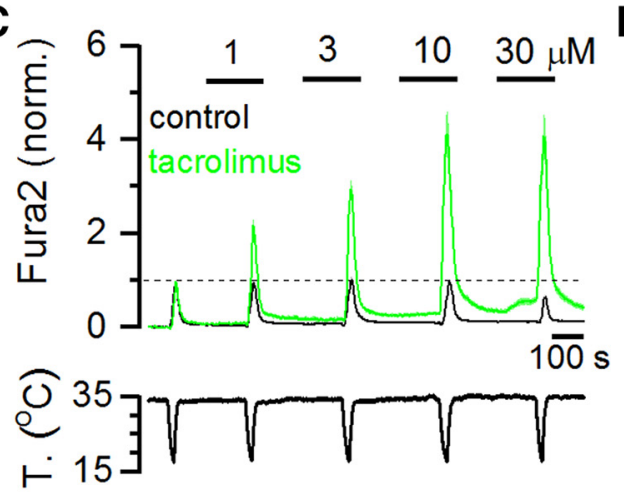

E
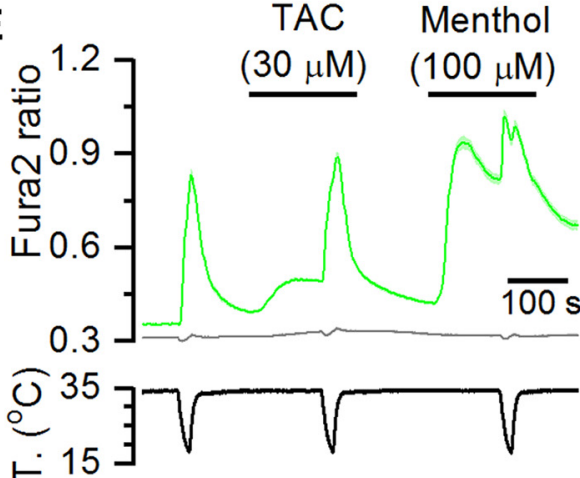

G

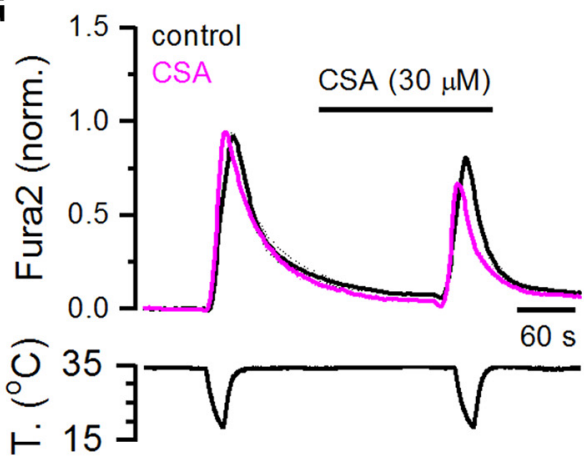

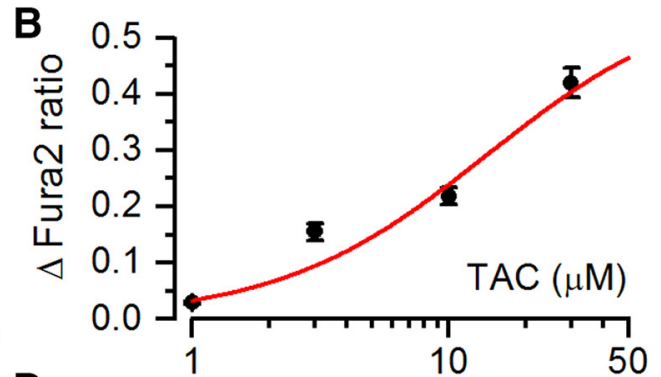

D

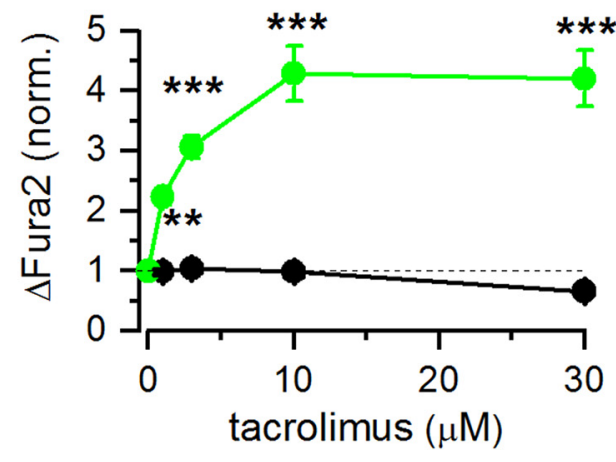

F

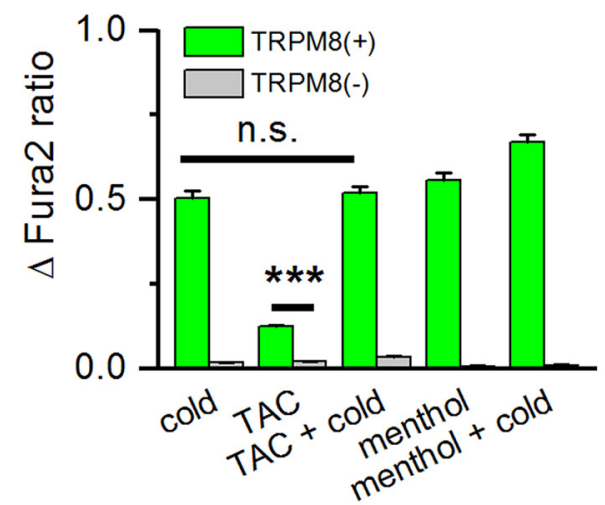

H

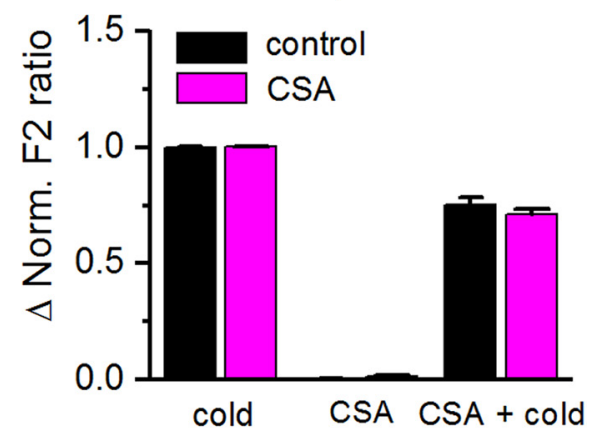

Figure 1. TAC activates recombinant TRPM8 channels and potentiates cold-evoked responses. $A$, Average \pm SEM fura-2 ratio changes in HEK293 cells stably expressing rat TRPM8 during sequential application of TAC at different concentrations $(n=105)$. $\boldsymbol{B}$, Dose-response curve of TAC effects on TRPM8-expressing cells. Data have been fitted with a logistic function ( $\mathrm{EC}_{50}=14.1 \pm$ $25.9 \mu \mathrm{M}$ ). C, Average \pm SEM time course of fura-2 ratio in HEK293-expressing mouse TRPM8 during consecutive application of cold pulses in control solution (black trace, $n=15$ ) or in the presence of increasing TAC concentrations (green trace, $n=16$ ). Bottom, Time course of the corresponding temperature ramps. In the absence of TAC, the response to cold was relatively stable, whereas in the presence of TAC, the response to cold was strongly sensitized. Responses in individual cells have been normalized to their response to the first cooling pulse. $D$, Summary plot of the effect of different doses of TAC on the amplitude of cold-evoked responses in mTRPM8 cells. ${ }^{* *} p<0.01$ (ANOVA test in combination with Bonferroni's post hoc test). ${ }^{* * *} p<0.001$ (AN0VA test in combination with Bonferroni's post hoc test). E, Average \pm SEM fura-2 ratio responses to cold, TAC $(30 \mu \mathrm{M})$, and menthol $(100 \mu \mathrm{M})$ in HEK293 cells transiently transfected with human TRPM8 and GFP. Green represents GFP $(+)$ cells $(n=132)$. Gray represents GFP $(-)$ cells $(n=87)$. $\boldsymbol{F}$, Summary of mean responses in cells transfected with hTRPM8 (green bars) to the different agonists. Gray represents the responses of untransfected, GFP( - ) cells. TAC produced a significant activation of hTRPM8 $\left({ }^{* * *} p<0.001\right.$; unpaired Student's $t$ test). G, Average \pm SEM fura- 2 ratio changes in HEK293 cells stably expressing rat TRPM8 during application of two cooling ramps. For the black traces $(n=25)$, cooling ramps were delivered in control solution. For the pink traces $(n=107)$, the second cooling ramp was applied in the presence of $30 \mu \mathrm{m}$ cyclosporine (CSA). $\boldsymbol{H}$, Histogram summarizing the effects of cyclosporine on cold-evoked calcium responses during the protocol shown in $\mathbf{G}$. No significant differences were found between the cells perfused with control solution or cyclosporine (unpaired Student's $t$ test). 

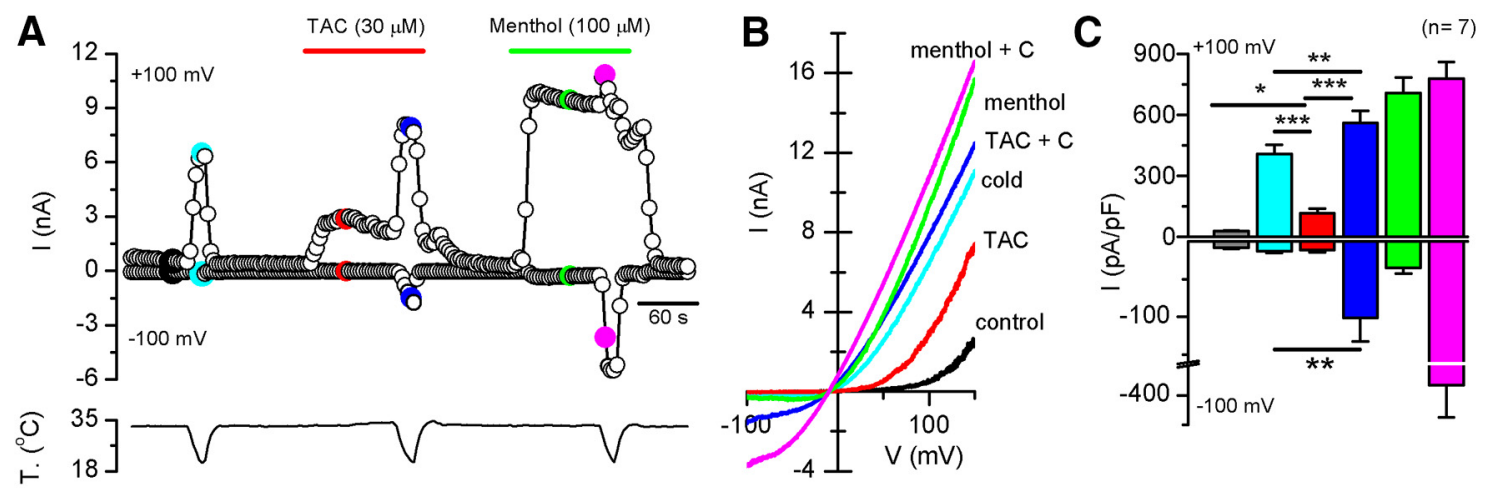

D

$\mathrm{E}$
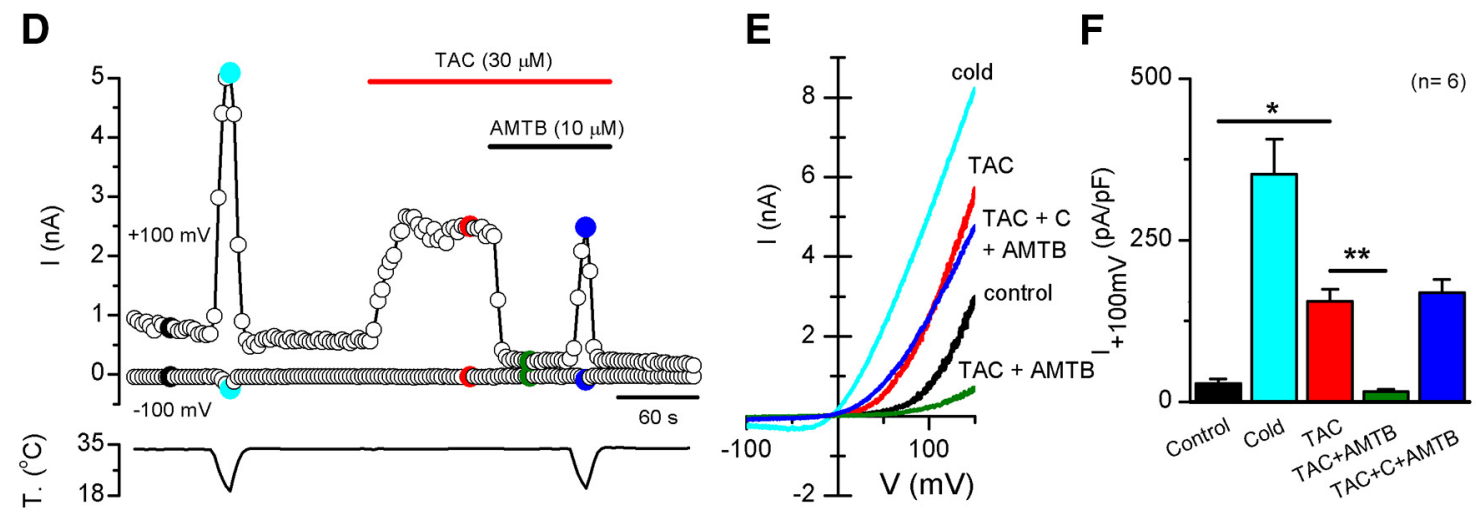

Figure 2. TAC activates TRPM8-mediated whole-cell currents in HEK293 cells. A, Representative time course of whole-cell currents at -100 and $100 \mathrm{mV}$ in HEK293 cell transiently transfected with mTRPM8 during application of agonists. Bottom, Simultaneous recording of the bath temperature during the experiment. $B, I-V$ relationship of responses shown in $A$, obtained with a $400 \mathrm{~ms}$ voltage ramp from -100 to $150 \mathrm{mV}$. The color of individual traces matches the color at each particular time point in $A$. TAC evokes a nonselective cationic current with typical TRPM 8 features and potentiates the cold-evoked response. C, Bar histogram summarizing the mean current density values at 100 and $-100 \mathrm{mV}$ to the different stimuli shown in $A$, with the same color code. Statistical differences were evaluated by a one-way ANOVA, followed by Bonferroni's post hoc test. $\boldsymbol{D}$, Representative time course of whole-cell currents at -100 and $100 \mathrm{mV}$ during a protocol in which the effect of AMTB was studied. AMTB $10 \mu$ m totally abolished TAC-evoked currents. Bottom, Simultaneous recording of the bath temperature during the experiment. $E$, I- $V$ relationship of responses shown in $\boldsymbol{D}$. The color of the $I-V$ curves matches the colored time points in $\boldsymbol{D}$. AMTB also blocks the voltage-dependent activation of TRPM8 at basal temperature. $\boldsymbol{F}$, Bar histogram summarizing the mean current density values at $100 \mathrm{mV}$ to the different stimuli applied in $\boldsymbol{D}$. Statistical differences were evaluated by a one-way ANOVA, followed by Bonferroni's post hoc test. ${ }^{*} p<0.05$, ${ }^{* *} p<0.01$, ${ }^{* * *} p<0.001$.

repeated in the presence of $800 \mu \mathrm{M}$ menthol, a saturating concentration, to obtain a $\mathrm{G}_{\max }$ value for TRPM8 activity.

Figure $3 A$ shows a representative example of a family of currents recorded in a cell expressing mTRPM8 during $100 \mathrm{~ms}$ voltage steps ranging from -80 to $240 \mathrm{mV}$. The average steady-state $I-V$ and $G-V$ curves for the different conditions are shown in Figure $3 B$ and Figure $3 C$, respectively. Analysis of these curves revealed a strong leftward shift of the activation curve in the presence of the three agonists, with a change in the voltage for half-maximal activation $\left(V_{1 / 2}\right)$ from $153 \pm 7 \mathrm{mV}$ in control to $106 \pm 10 \mathrm{mV}$ in the presence of TAC (calculated from $G-V$ ) (Fig. $3 D$ ). The shift in $V_{1 / 2}$ with respect to control conditions was highly significant $(p<0.0001)$. Menthol $(10 \mu \mathrm{M})$ and AITC (10 $\mathrm{mm}$ ) had similar effects on $V_{1 / 2}$ (Fig. 3D).

To characterize the effect of the different agonists on TRPM8 gating kinetics, we studied the changes in the time course of current activation during voltage steps to $120 \mathrm{mV}$ (Fig. 3E) and their relaxation upon return to $-80 \mathrm{mV}$ (Fig. $3 F$ ). For a better comparison, currents were normalized to their steady-state values. Both menthol and TAC produced a clear slowing of the gating kinetics during depolarization to $120 \mathrm{mV}$ and after the return to $-80 \mathrm{mV}$. In contrast, AITC clearly accelerates the activation kinetics (Fig. $3 E$ ), without affecting the current relaxation kinetics upon repolarization to $-80 \mathrm{mV}$ (Fig. $3 F$ ). Currents in control or during AITC application were adequately fitted with a single exponential (data not shown). In contrast, the currents in
TAC or menthol required a double exponential. To quantify the differences in kinetics produced by the three chemical agonists in more detail, we compared the rise time to $95 \%$ of the initial value. These results are shown in Figure $3 G, H$ for the activation and deactivation time course, respectively.

These results show that the mechanism of action of TAC on TRPM8 gating resemble those of menthol and are different of the AITC gating mechanism (Janssens et al., 2016).

\section{Gating of TRPM8 by TAC in planar lipid bilayers}

To test the possible direct action of TAC on TRPM8 gating, we evaluated channel activity in a reconstituted system. The myctagged rat TRPM8 protein was purified from HEK293 cells stably expressing the channels using immunoprecipitation, and incorporated into planar lipid bilayers as previously described (Zakharian et al., 2010). Similarly to other TRPM8 agonists (Zakharian et al., 2010; Asuthkar et al., 2015), TAC led to TRPM8 channel openings only in the presence of its prime gating factor, $\mathrm{PIP}_{2}$. Incubation of TRPM8 with TAC alone (30 $\mu \mathrm{M})$ for a few hours (2-3 h of testing) was insufficient to activate the channel (data not shown). Similarly, PIP $_{2}$ alone $(2.5 \mu \mathrm{M})$ did not induce channel openings at RT (data not shown). However, TRPM8 opened promptly soon after the addition of $2.5 \mu \mathrm{M} \mathrm{PIP}_{2}$ to TAC (Fig. 4A). In the presence of TAC, TRPM8 exhibited outward currents with a mean slope conductance of $\sim 31 \mathrm{pS}$, and inward conductance of $\sim 20$ pS. The TAC-induced TRPM8 channel openings also dem- 

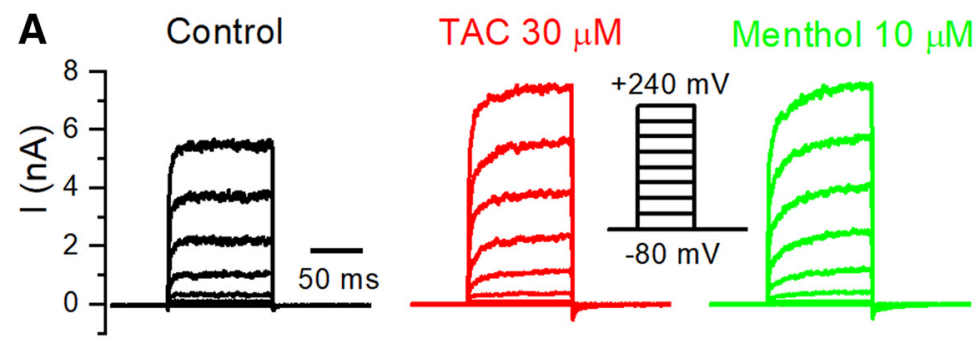

AITC $10 \mathrm{mM}$

B

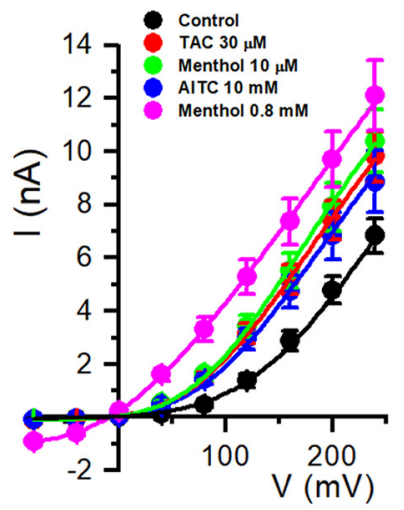

C

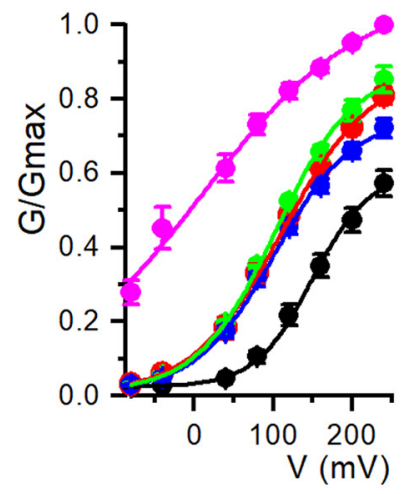

D

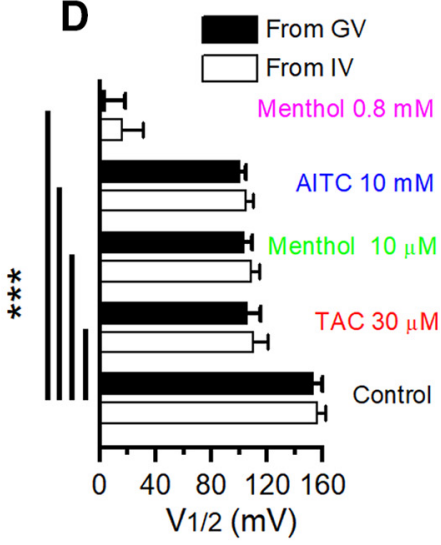

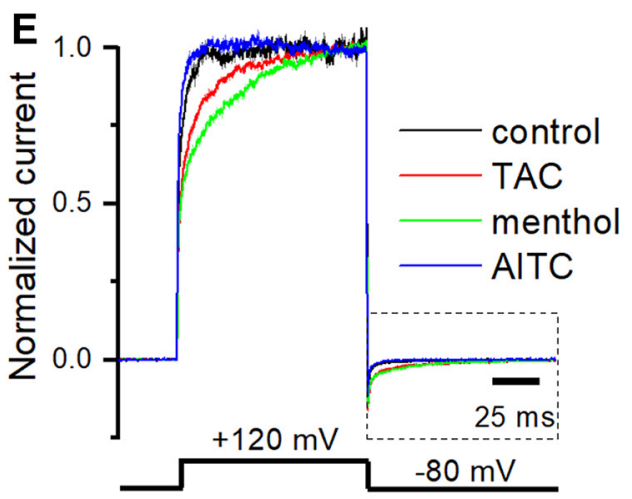

$\mathbf{F}$

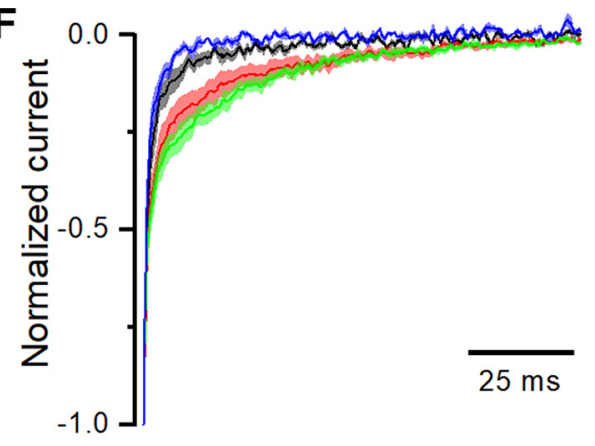

G

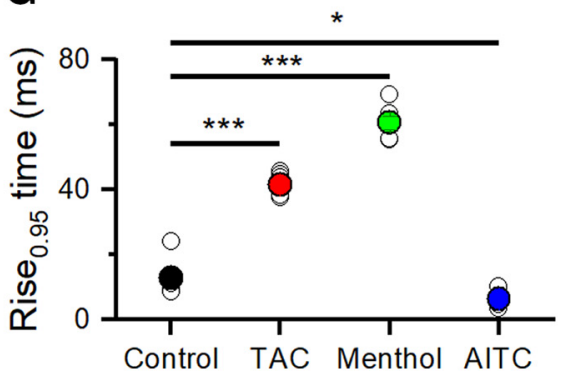

H

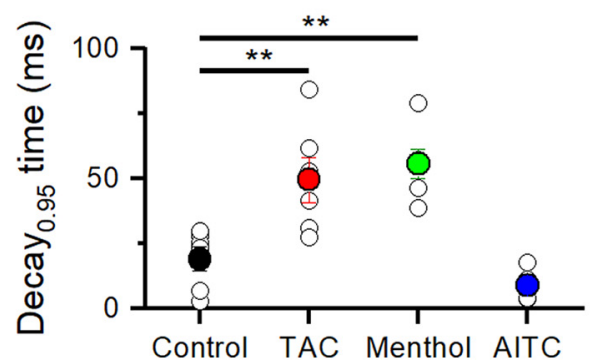

Figure 3. Biophysical characterization of TAC effects on TRPM8 gating. $A$, Whole-cell TRPM 8 currents in response to the indicated voltage step protocol (from -80 to $240 \mathrm{mV}, \Delta v=40 \mathrm{mV}$ ) in control conditions and in the presence of TAC $(30 \mu \mathrm{M})$, menthol $(10 \mu \mathrm{M})$, and AITC $(10 \mathrm{~mm})$ at $24^{\circ} \mathrm{C}$. Note the variable effect of agonists on activation kinetics. $B$, Averaged $(n=6)$ steady-state $I-V$ curves extracted from individual cells after application of Protocol A. The lines indicate the fitting to a linearized Boltzmann equation (see Materials and Methods). $\boldsymbol{C}$, Averaged $(n=6)$ voltage dependence activation curves in control conditions and in the presence of the different agonists. Conductance $(\mathrm{G})$ was calculated as the steady-state current divided by the driving force (Driving force $\left.=V_{\text {test }}-E_{\text {rev }}\right)$, and normalized to the estimated maximal conductance $\left(G_{\max }\right)$, which was the $G$ value at $240 \mathrm{mV}$ in the presence of $0.8 \mathrm{~mm}$ menthol. $D$, Mean $(n=6) V_{1 / 2}$ values calculated from fitting the individual $I-V$ curves to the linearized Boltzmann equation (white bars) or the individual $\mathrm{G} / \mathrm{G}_{\max }-V$ curves fitted to the Boltzmann equation (black bars). All three agonists produced similar shifts in $V_{1 / 2}$ values at the indicated concentrations. Statistical differences were evaluated by a one-way ANOVA, followed by Bonferroni's post hoc test. $\boldsymbol{E}$, Averaged TRPM8 current during a voltage step from -80 to $120 \mathrm{mV}$, in control condition and in the presence of the different agonists. Currents were normalized to their steady-state amplitude after baseline subtraction. $\boldsymbol{F}$, Averaged \pm SEM TRPM8 deactivation kinetics at $-80 \mathrm{mV}$ obtained from current tails after a voltage step to $120 \mathrm{mV}$ (box bounded by dotted line in $\boldsymbol{E}$ ), in control condition and in the presence of the different agonists. The current was normalized to the maximum value, and baseline was subtracted. $\mathbf{G}$, Mean values of the current activation time course, measured from baseline to $95 \%$ amplitude, for voltage steps to $120 \mathrm{mV}$. $\boldsymbol{H}$, Mean values of current deactivation time course at $-80 \mathrm{mV}$, measured from baseline to $95 \%$ amplitude, following a voltage step to $120 \mathrm{mV}$. $\boldsymbol{F}, \boldsymbol{G}$, Statistical differences were evaluated with a one-way ANOVA, followed by Bonferroni's post hoc test. ${ }^{*} p<0.05,{ }^{* *} p<0.01,{ }^{* * *} p<0.001$. 
A
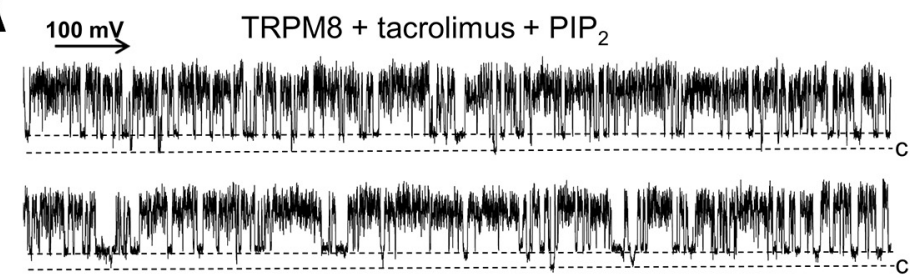

$-100 \mathrm{mV}$

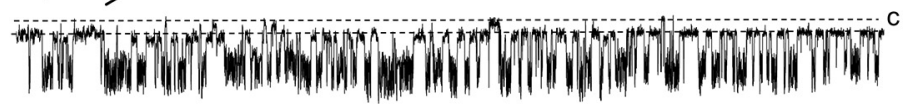

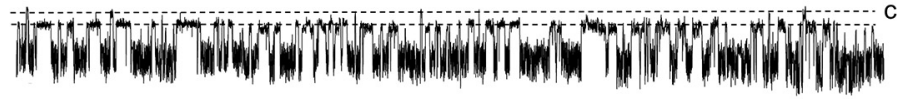

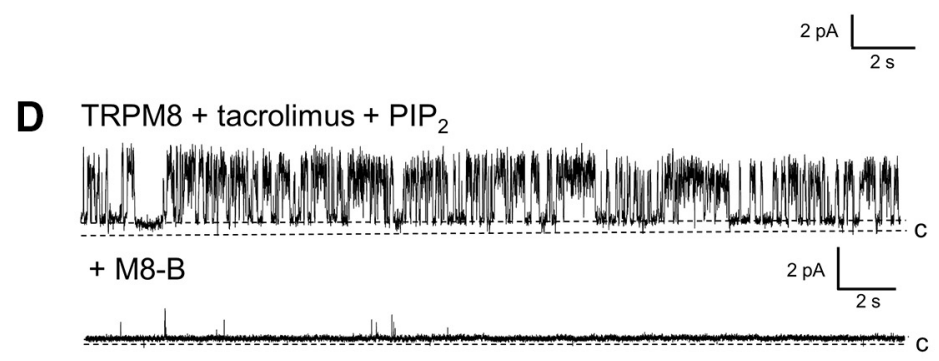

B
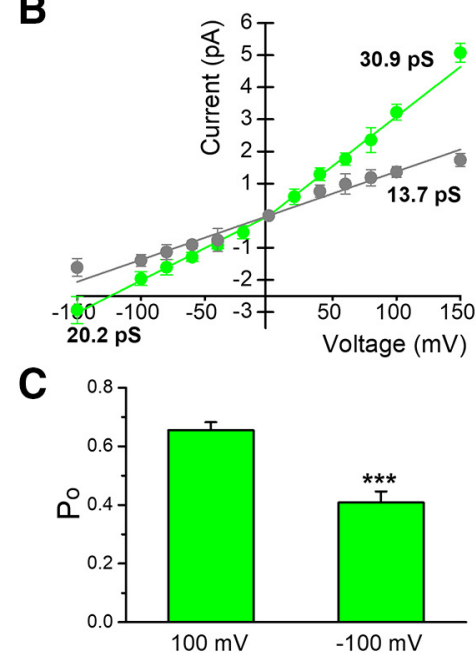

E

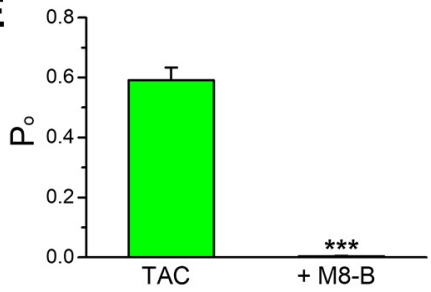

Figure 4. TAC activates purified TRPM8 in planar lipid bilayers. A, Representative single-channel recordings of TRPM 8 obtained at $100 \mathrm{mV}$ and $-100 \mathrm{mV}$ showing the activation with $30 \mu \mathrm{m}$ TAC in the presence of $2.5 \mu \mathrm{MPIP}, \cdot B, I-V$ curve of TRPM8 single-channel current during TAC activation at different membrane potentials, showing the main conductance of outward and inward currents (green trace), and a lower subconductance state (gray trace).C, Bar graph represents open probability (Po) values at 100 and $-100 \mathrm{mV}$ in the presence of TAC and PIP ${ }_{2}$. Data represent mean \pm SEM from 13 experiments; number of events $=28,935$. Po was significantly higher at $100 \mathrm{mV}$ ( ${ }^{* * *} p<0.001$, paired Student's $t$ test). $\boldsymbol{D}$, Representative current traces demonstrating inhibition of TAC-induced TRPM8 activity with M8-B $(20 \mu \mathrm{M})$. TRPM8 was activated with $30 \mu \mathrm{m} \mathrm{TAC}$ in the presence of $2.5 \mu \mathrm{m} \mathrm{PIP}$. Traces were obtained at $100 \mathrm{mV}$. E, Bar graph summarizing the inhibition produced by M8-B on Po. Data represent mean \pm SEM from four experiments $\left({ }^{* * *} p<0.001\right.$, paired Student's $t$ test).

onstrated a distinct subconductance state of $\sim 14 \mathrm{pS}$ (Fig. $4 A, B)$. In addition to the differences in conductance for currents flowing in the inward or outward direction, an outward rectification was also evident in open probability $\left(\mathrm{P}_{\mathrm{o}}\right)$ (Fig. $\left.4 \mathrm{C}\right)$. Next, we tested the effect of a specific TRPM8 antagonist on TAC-induced channel activity. As shown in Figure 4D, E, the TRPM8 inhibitor M8-B essentially eliminated channel openings. Together, these results establish a direct agonistic action of TAC on TRPM8 channels, and also demonstrate the requirement of its activity on $\mathrm{PIP}_{2}$.

TAC activates the menthol-insensitive TRPM8-Y745H mutant but fails to potentiate its cold response

A single tyrosine residue (Y745), located on transmembrane segment 1 according to recent Cryo-EM structural analysis (Yin et al., 2018), is essential for the activating actions of menthol on TRPM8 channels (Bandell et al., 2006; Mälkiä et al., 2009). These mutant channels are completely insensitive to menthol but retain the normal responsiveness to cold and voltage exhibited by WT channels.

Using calcium imaging, we found that TAC activates mouse TRPM8-Y745H (Fig. 5A,B). On average, the amplitude of the $\left[\mathrm{Ca}^{2+}\right]_{i}$ elevation after application of $30 \mu \mathrm{M}$ TAC, normalized to the response to a cold ramp in control conditions, was $0.20 \pm$ 0.008 in WT channels $(n=66)$ compared with $0.17 \pm 0.007$ in TRPM8-Y745H $(n=38, p<0.05)$. Remarkably, despite a normal response to cold or TAC, the TRPM8-Y745H mutant showed no potentiation of the cold response by TAC (ratio of TAC plus cold $/$ cold $=1.09 \pm 0.05)$. In contrast, the WT channel showed a strong potentiation $(1.4 \pm 0.08)$ (Fig. $5 B, p<0.01$ ).
To confirm these differences, we examined the effects of TAC on whole-cell currents in WT and mutant channels (Fig. 5C). The current generated by TAC was normalized to the cold response evoked in control conditions in the same cell, at a potential of 100 $\mathrm{mV}$. On average, TAC current was $0.27 \pm 0.04$ in WT channels and $0.30 \pm 0.04$ in the $\mathrm{Y} 745 \mathrm{H}$ mutant, confirming that the TRPM8-Y745H mutants maintain their normal sensitivity to TAC. In the same cells, menthol $(100 \mu \mathrm{M})$ had no effect, as expected for the $\mathrm{Y} 745 \mathrm{H}$ mutant (data not shown). Moreover, whole-cell recordings confirmed that the potentiation of the cold-evoked response by TAC was absent in the $\mathrm{Y} 745 \mathrm{H}$ mutant $(\mathrm{WT}$ ratio $=1.39 \pm 0.05$ vs TRPM8 $-\mathrm{Y} 745 \mathrm{H}$ ratio $=0.83 \pm 0.09)$ (Fig. 5D).

Next, we explored TAC sensitivity in the TRPM8-N799A mutant. This residue was shown to mediate responses to icilin, a different TRPM8 agonist (Chuang et al., 2004). TRPM8-N799A mutants behaved like TRPM8 WT channels, with normal responses to TAC and the potentiation of the cold response (Fig. $5 C, D)$, suggesting that the effects of TAC on TRPM8 do not involve the icilin-binding site.

These results suggest a mode of action of TAC independent of the putative menthol and icilin binding sites and unveil the importance of the Y745 residue in the allosteric coupling between cold and TAC activation of TRPM8.

Effects of TAC on other thermoTRP channels

Next, we tested the effects of TAC on other thermally sensitive TRP channels (Dhaka et al., 2006). As shown in Figure 6A, TAC $(30 \mu \mathrm{M})$ had no activating effect on rat TRPV1 or mouse TRPM3. 
A

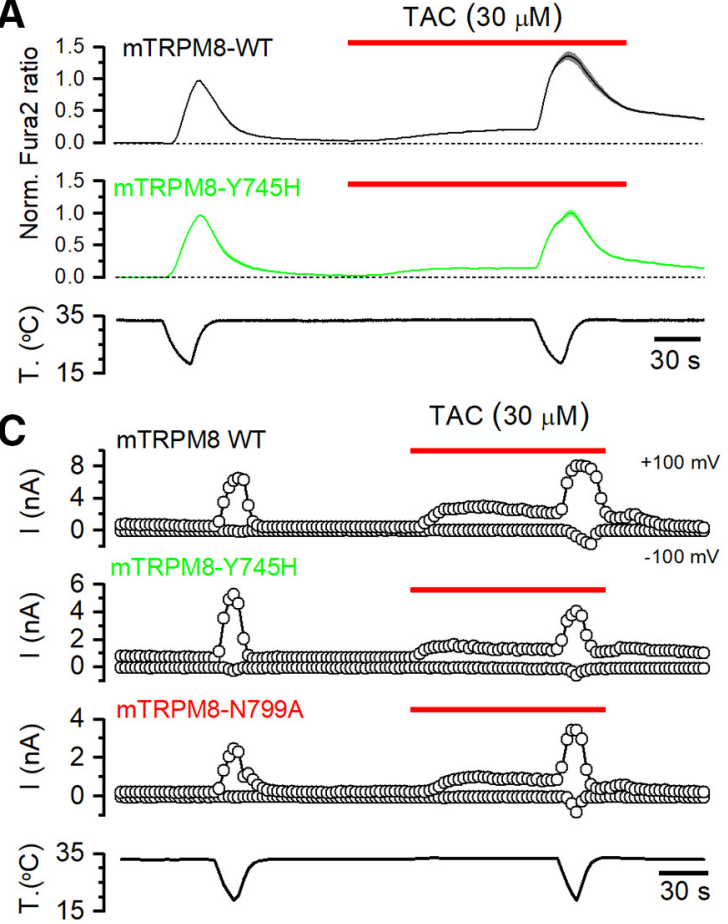

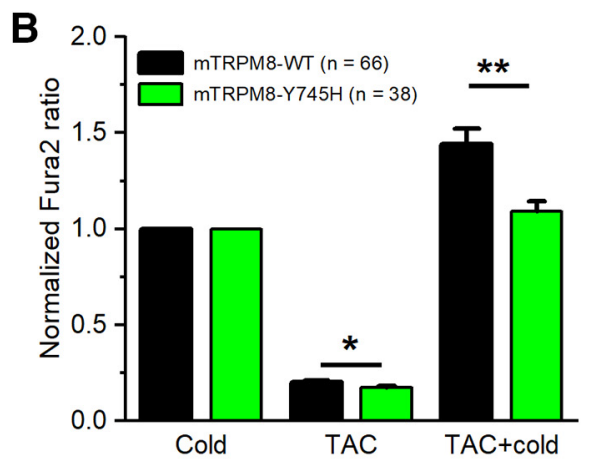

D

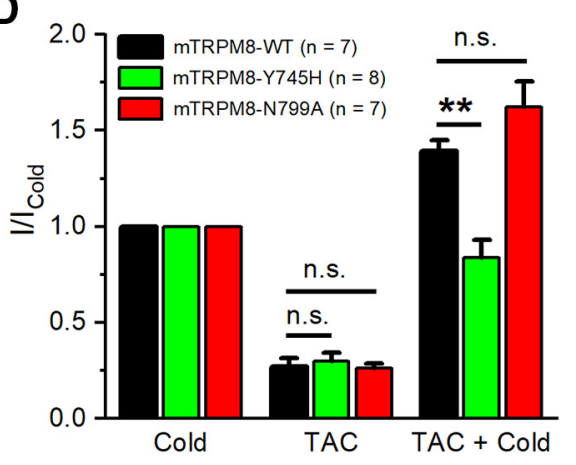

Figure 5. TAC activates the menthol- and the icilin-insensitive TRPM8 mutants. $A$, Averaged \pm SEM fura-2 ratio fluorescence of mouse TRPM8-transfected HEK293 cells during cooling, TAC (30 $\mu \mathrm{M}$ ) and the combined application of TAC and cooling. Records have been baseline-subtracted and the average trace normalized to the initial response to cold. Top to bottom, Calcium responses of WT TRPM8, the menthol-insensitive TRPM8 - $7745 \mathrm{H}$ mutant, and a representative recording of the temperature time course in the chamber during the recording. $\boldsymbol{B}$, Histogram of mean response amplitudes to the different stimuli, normalized to the initial cold response. Note the lack of potentiation of the cold-evoked response by TAC in the menthol-insensitive mutant. Statistical differences were evaluated by an unpaired Student's $t$ test. C, Representative traces of whole-cell recordings exploring the effect of cold and TAC in two different TRPM8 mutants. Top to bottom, Currents, measured at -100 and $100 \mathrm{mV}$, in WT mouse TRPM8, the menthol-insensitive TRPM8 -Y745H mutant, and the icilin-insensitive TRPM8 -N799A mutant. Bottom, Representative recording of the temperature change in the chamber during the protocol. $\boldsymbol{D}$, Histogram of the average current values to the different agonists in TRPM8 WT and the different mutants during the protocol shown in C. For each cell, current responses were normalized to the initial cold-evoked response. Statistical differences for the response to each agonist in the different TRPM 8 constructs were evaluated with a one-way ANOVA, followed by Bonferroni's post hoc test. ${ }^{*} p<0.05,{ }^{* *} p<0.01$.
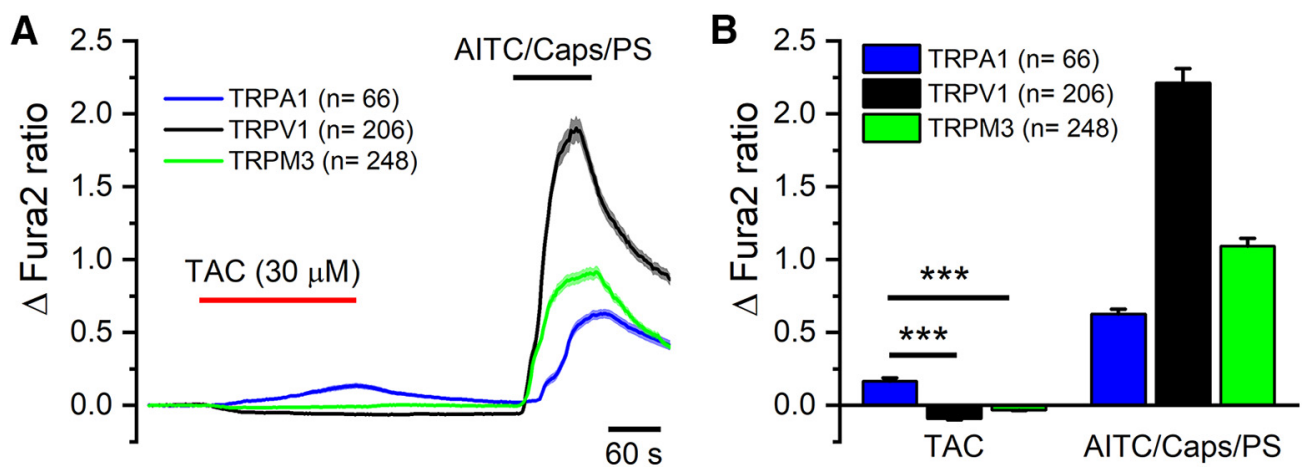

Figure 6. TAC activates human TRPA1 channels. $A$, Averaged \pm SEM fura- 2 fluorescence ratio of HEK 292 cells transfected with human TRPA1 (blue trace), rat TRPV1 (black trace), or mouse TRPM 3 (green trace) during applications of TAC ( $30 \mu \mathrm{M})$ and their canonical agonists capsaicin (100 nM), AITC ( $50 \mu \mathrm{M})$, and pregnenolone sulfate (PS, $50 \mu \mathrm{m})$. B, Bar histogram summarizing the effect of TAC or the canonical agonists, capsaicin, AITC, or PS, on fura-2 fluorescence ratio. Individual records have been baseline-subtracted. TAC produced a significant elevation in [Ca $\left.{ }^{2+}\right]_{i}$ in TRPA1transfected cells compared with TRPV1- or TRPM3-transfected cells $\left({ }^{* *} p<0.001\right.$, one-way ANOVA followed by Bonferroni's post hoc test). ${ }^{* * *} p<0.001$.

In contrast, the same concentration of TAC activated human TRPA1, with a slowly rising $\left[\mathrm{Ca}^{2+}\right]_{i}$ response. The activating effects of TAC on TRPA1 were more modest than those produced by its canonical agonist AITC (Fig. 6B). We noticed that application of TAC produced a modest inhibition of basal calcium levels in cells expressing TRPV1 or TRPM3, suggesting some inhibitory effect on background activity at this temperature (i.e., $34^{\circ} \mathrm{C}$ ). The effects of TAC on recombinant TRPM8 and TRPA1 channels motivated a deeper characterization of its action on primary sensory neurons.
TAC activates TRPM8-expressing cold-sensitive neurons and potentiates their cold response

TRPM8-expressing neurons represent only a small fraction of all DRG neurons (McKemy et al., 2002; Takashima et al., 2007; Dhaka et al., 2008). We used a BAC-transgenic mouse expressing enhanced YFP under the Trpm 8 promoter, $\operatorname{Trp} m 8^{\mathrm{BAC}}$-EYFP (Morenilla-Palao et al., 2014) and intracellular $\mathrm{Ca}^{2+}$ imaging to identify TRPM8-expressing neurons in DRG cultures. Confirming our previous finding in this transgenic mouse line (Morenilla-Palao et al., 2014), most $\mathrm{YFP}(+)$ neurons were 
A
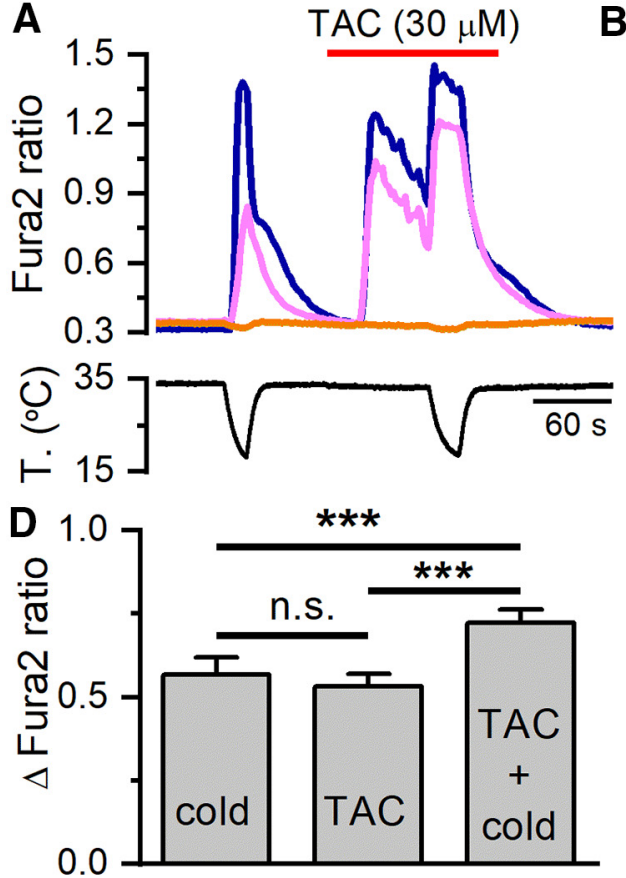

$F$

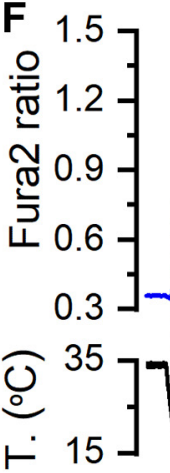

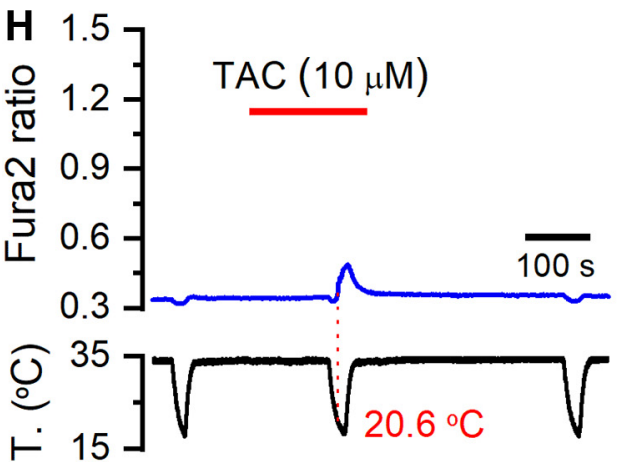

B

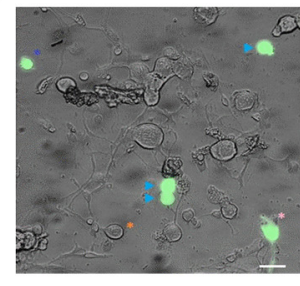

C

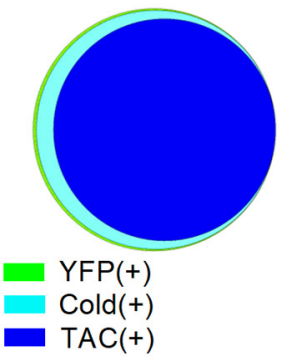

E

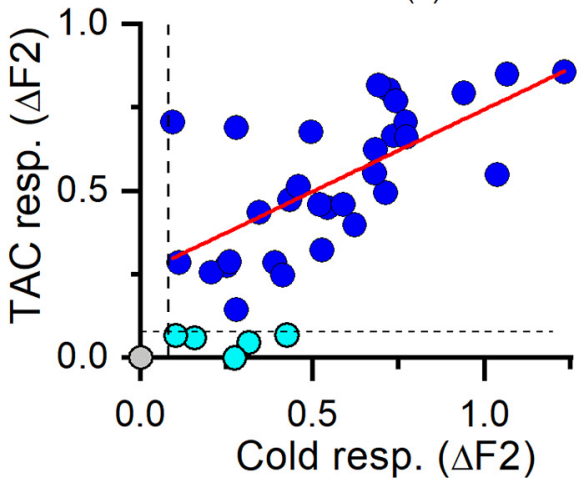

G

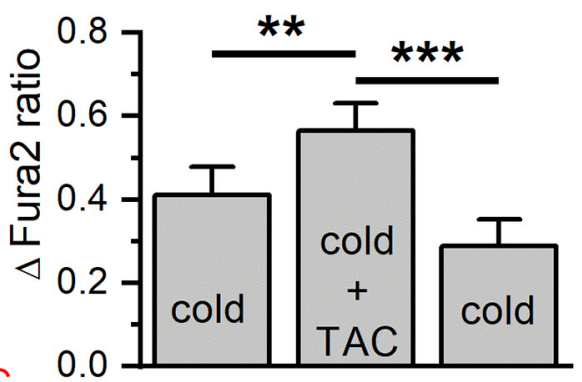

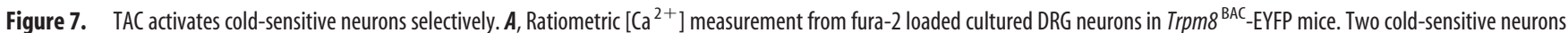
(blue and magenta traces) increased their $\left[\mathrm{Ca}^{2+}\right.$ ] level during the cooling ramp. The same neurons also responded to $30 \mu \mathrm{M}$ TAC, and their response to cold was potentiated. The cold-insensitive neuron (orange trace) did not respond to any of these stimuli. $B$, Representative image of a DRG culture from a $\operatorname{Trpm} 8^{\mathrm{BAC}}$-EYFP mouse. $\boldsymbol{A}$, Traces correspond to the neurons marked with the same colored asterisk: orange for $\mathrm{YFP}(-)$, blue and magenta for YFP $(+)$. Three additional YFP( + ) neurons, marked with blue arrowheads, also responded to cold and TAC. Scale bar, $20 \mu \mathrm{m}$. $\boldsymbol{C}$, Venn diagram showing the strong overlap between YFP( + ) neurons (green, $n=37$ ), the response to cooling (cyan, $n=36$ ), and the response to TAC (blue, $n=31$ ). In this sample, none of the YFP $(-$ ) neurons $(n=130$ ) responded to TAC. $D$, Bar histogram showing the average amplitude of the responses to cold, to TAC, and to cold in the presence of TAC. Amplitudes were similar for cold and TAC, whereas the responses to cold were significantly higher in the presence of TAC. One-way ANOVA for repeated measures followed by Bonferroni's post hoc test. $\boldsymbol{E}$, Correlation between amplitude of cold-and TAC-evoked responses in individual DRG neurons. Black dotted lines indicate the threshold amplitude established for considering a positive response. Blue points represent the neurons that responded to cold and TAC $(n=31)$. Cyan points represent the neurons that responded to cold but did not respond to TAC $(n=5)$. Note the small cold-evoked response in neurons unresponsive to TAC. Gray point represents the single YFP( + ) neuron that did not respond to cold or TAC. The linear fit to the blue points (red line) yielded a correlation coefficient $\left(r^{2}\right)$ of 0.42 . $F$, Representative trace of fura-2 ratio fluorescence in a DRG neuron during three consecutive cooling ramps. Note the strong, reversible potentiation of the cold-evoked response in the presence of $10 \mu \mathrm{m}$ TAC. Red numbers indicate the temperature at which the measured signal (F340/F380) deviated by at least 4 times the SD of its baseline (i.e., temperature threshold). $\mathbf{G}$, Bar histogram summarizing the effect of 10 $\mu \mathrm{M}$ TAC on the amplitude of the cold-evoked response. One-way ANOVA for repeated measures followed by Bonferroni's post hoc test. $\boldsymbol{H}$, Time course of fura- 2 ratio in a YFP( +$)$, which was not activated in control conditions (i.e., cold insensitive) but was recruited in the presence of $10 \mu \mathrm{m} \mathrm{TAC.} \mathrm{I,} \mathrm{Temperature} \mathrm{threshold} \mathrm{of} \mathrm{individual} \mathrm{YFP(+)} \mathrm{neurons} \mathrm{to} \mathrm{cold} \mathrm{or} \mathrm{cold} \mathrm{plus} 10 \mu \mathrm{m}$ TAC. The mean temperature threshold (red triangles) shifted from $23.9 \pm 0.9^{\circ} \mathrm{C}$ in control solution to $27.8 \pm 0.8^{\circ} \mathrm{C}$ in the presence of $10 \mu \mathrm{M} \mathrm{TAC}\left(p<0.001, n=14\right.$, paired Student's $t$ test). ${ }^{* *} p<0.01,{ }^{* * *} p<0.001$. 

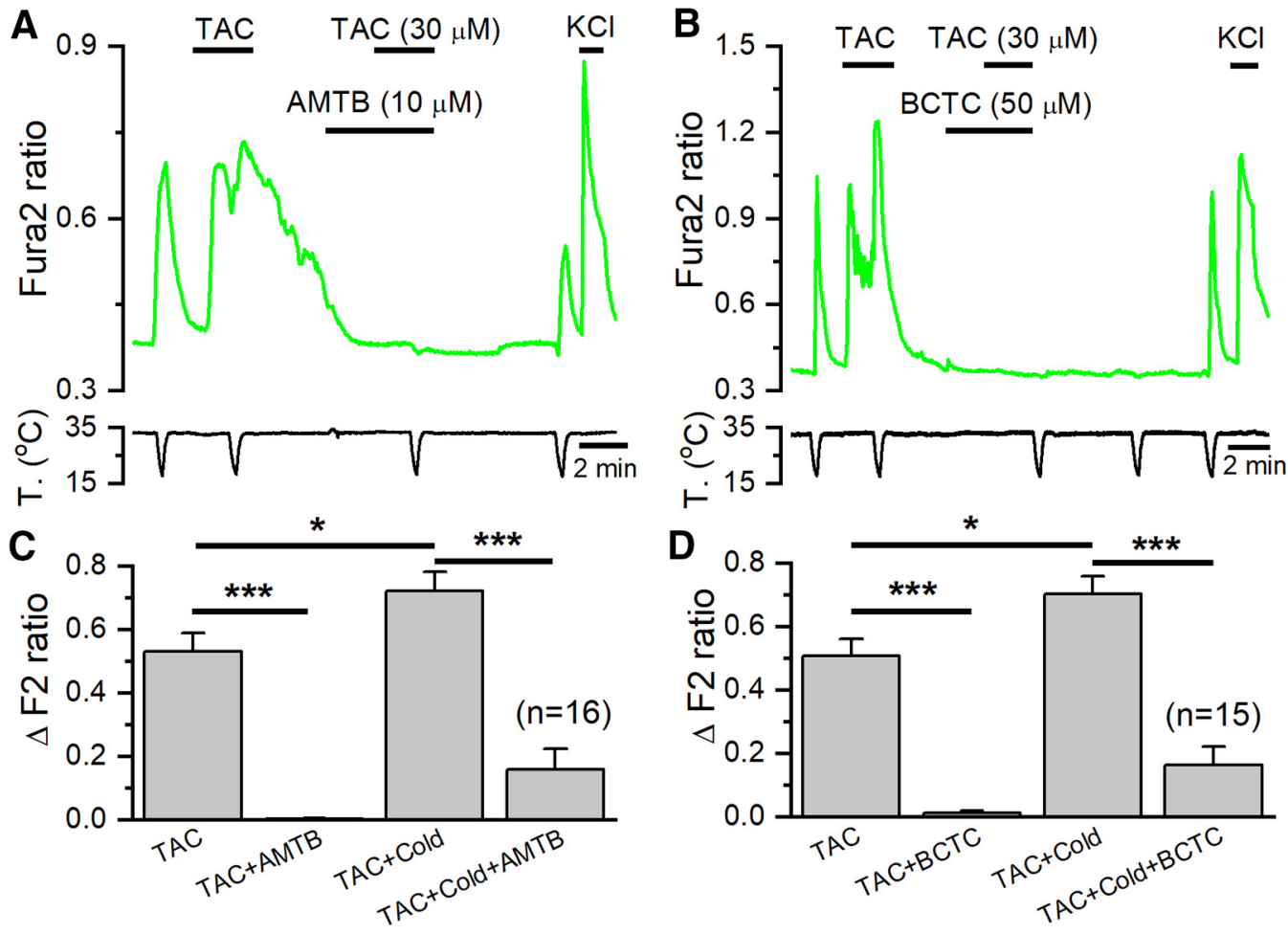

Figure 8. TRPM8 antagonists block the excitatory effects of TAC on mice DRG neurons. $\boldsymbol{A}$, Ratiometric $\left[\mathrm{Ca}^{2+}\right.$ ] levels in a fura-2 AM-loaded cultured DRG neuron from a Trpm $8^{\text {BAC }}$-EYFP mouse, showing the response to cold and TAC in control conditions and in the presence of the TRPM8 blocker AMTB (10 $\mu \mathrm{M})$. $B, A$ similar protocol in the presence of BCTC ( $50 \mu \mathrm{M})$, a different, structurally unrelated, TRPM8 blocker. C, Bar histograms summarizing the effects of AMTB ( $n=16)$, and (D) BCTC $(n=15)$ on cold-and TAC-evoked responses. Statistical differences evaluated with one-way ANOVA followed by Bonferroni post hoc test. ${ }^{*} p<0.05,{ }^{* * *} p<0.001$.

activated by cold (36 of 37), but only 1 in $130 \mathrm{YFP}(-)$ was cold-sensitive, suggesting a very good match between YFP fluorescence and TRPM8 expression (Fig. $7 B, C$ ).

Application of $30 \mu \mathrm{M}$ TAC activated the majority of TRPM8expressing thermoreceptor neurons (31 of 36), identified by the expression of YFP and by their response to a cold temperature ramp (Fig. $7 A, C$ ). In the presence of $30 \mu \mathrm{M}$ TAC, the amplitude of cold-evoked responses also increased significantly in $\operatorname{YFP}(+)$ neurons (Fig. 7D). TAC and cold produced a similar activation of individual neurons, and the amplitude of both responses was strongly correlated $\left(r^{2}=0.42\right)$ (Fig. $\left.7 E\right)$. In contrast, none ( 0 of 130) of the $\mathrm{YFP}(-)$ neurons (i.e., those not expressing TRPM8) were activated by $30 \mu \mathrm{M}$ TAC, although they showed normal responses to $30 \mathrm{~mm} \mathrm{KCl}$ (data not shown).

We also examined the effects of lower concentration of TAC on DRG neurons. As shown in Figure $7 F$, at $10 \mu \mathrm{M}$, the effects of TAC on $\left[\mathrm{Ca}^{2+}\right]$ levels on a $\mathrm{YFP}(+)$ neuron were negligible. However, we found that this concentration of TAC sensitized the response of TRPM8-expressing neurons to cold in a reversible manner. This is a similar effect to that described for other chemical agonists of TRPM8 (McKemy et al., 2002; Voets et al., 2004). On average, the $\left[\mathrm{Ca}^{2+}\right]$ response to cold increased from $0.41 \pm$ 0.07 during the first cold ramp to $0.57 \pm 0.06$ during a second cold ramp, in the presence of TAC $(p<0.01, n=14)$ (Fig. $7 G)$. The larger amplitude in the cold-evoked response was accompanied by a shift in the response threshold of individual neurons toward warmer temperatures (Fig. $7 F, I$ ). On average, the threshold shifted by $\sim 4^{\circ} \mathrm{C}$, from a mean of $23.8 \pm 0.9^{\circ} \mathrm{C}$ in control to $27.8 \pm 0.7^{\circ} \mathrm{C}$ in the presence of $10 \mu \mathrm{M} \mathrm{TAC}(p<0.001, n=14)$. In addition, one $\mathrm{YFP}(+)$ neuron initially insensitive to cold became cold sensitive during the application of this TAC concentration, and this activation was reversible (Fig. $7 H$ ).
In agreement with the observations obtained in TRPM8transfected HEK293 cells, cyclosporine $(30 \mu \mathrm{M})$ failed to activate YFP(+) DRG neurons (0 of 37), or sensitize their responses to cold: the increase in cold-evoked fura- 2 ratio was $0.72 \pm 0.13$ in the presence of vehicle $(n=16)$, compared with $0.63 \pm 0.06$ in the presence of cyclosporine $(n=37)(p=0.40$, unpaired Student's $t$ test).

Collectively, these results indicate that TAC excites coldsensitive neurons that express TRPM8, and potentiates their cold response by shifting the threshold temperature to warmer temperatures.

\section{TRPM8 mediates TAC responses in DRG neurons}

Next, we explored whether TAC responses in cold-sensitive DRG neurons were mediated by TRPM8 activation. To this end, we combined two experimental strategies: a pharmacological approach using two different TRPM8 blockers and a genetic approximation, characterizing responses in TRPM8 KO mice. If TAC responses were mediated by TRPM 8 activation, they should be sensitive to TRPM8 antagonists. As shown in Figure $8 A, B$, this prediction was fulfilled; the responses to TAC in cold-sensitive DRG neurons were completely blocked by AMTB $(10 \mu \mathrm{M})$ and BCTC $(50 \mu \mathrm{M})$, two structurally unrelated TRPM8 antagonists (Almaraz et al., 2014). A summary of these results is shown in Figures $8 C, D$. Moreover, the $\left[\mathrm{Ca}^{2+}\right]_{i}$ elevation during cold ramps in the presence of TAC were also greatly reduced by these two antagonists $(p<0.001)$.

To confirm the effects of TAC on native TRPM8 channels, we examined responses to TAC in DRG cultures from a transgenic mouse line in which a farnesylated eGFP is expressed from the Trpm8 locus (TRPM8 ${ }^{E G F P f}$ ) in replacement of TRPM8, allowing the identification of putative TRPM8-expressing neurons 
A

A

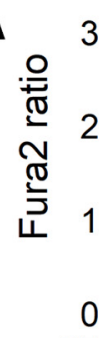

$\left.\begin{array}{l}3 \\ -1 \\ 1 \\ -1\end{array}\right]$

Trpm $8^{+/}$ TAC

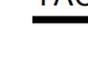

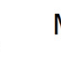
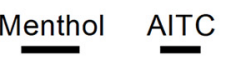

.

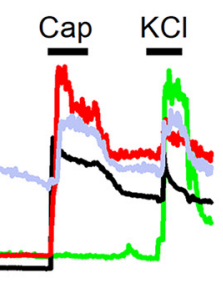

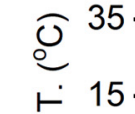

C
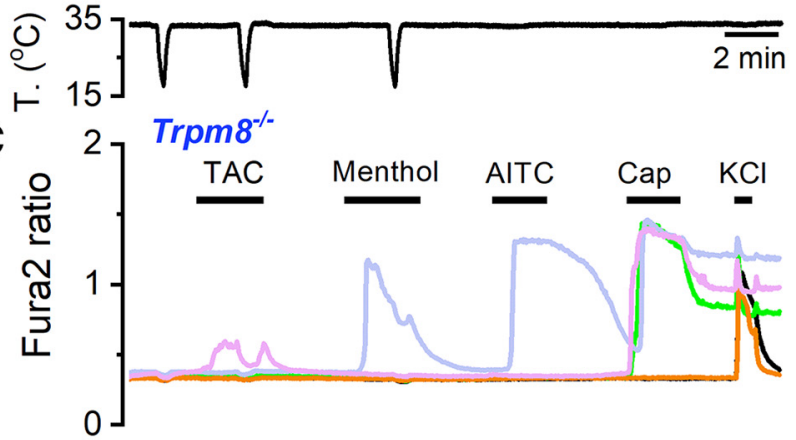

$\sqrt{ }$

$\overline{2 \min }$<smiles>C=CC1C=CC(CC)C1[As]</smiles>
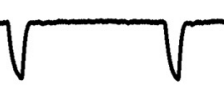

E

o

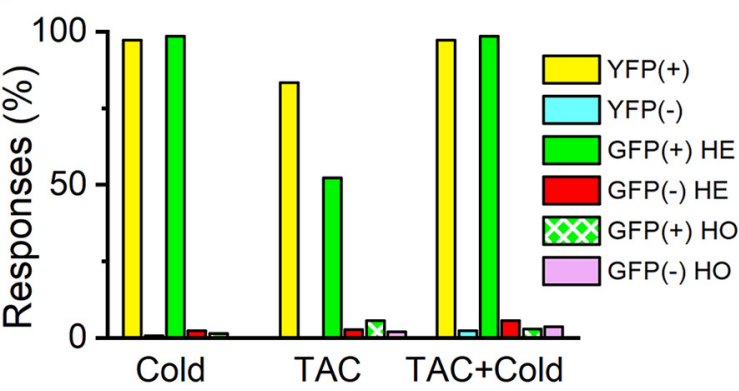

B

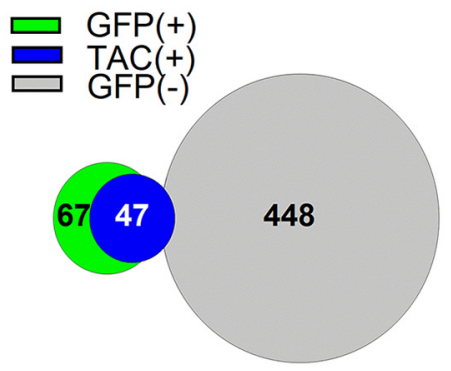

D

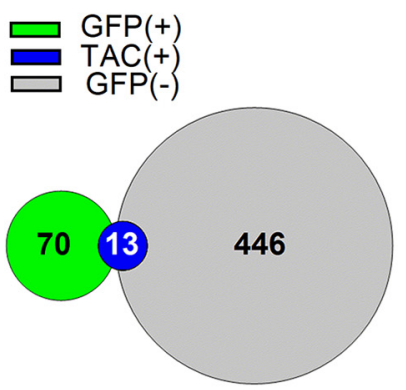

$F$

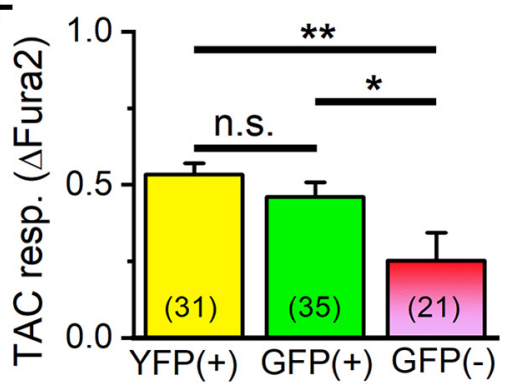

Figure 9. TRPM8 is the principal mediator of the excitatory effects of TAC on DRG neurons. $A$, Representative traces of fura- 2 ratio fluorescence in a Trpm $8^{E G F P f /+}$ DRG culture. Consecutive applications of cold, TAC $(30 \mu \mathrm{M})$, menthol (100 $\mu \mathrm{M})$, AITC (100 $\mu \mathrm{M})$, capsaicin $(100 \mathrm{nM})$, and high $\mathrm{K}^{+}(30 \mathrm{~mm})$ were used to define the phenotype of each neuron. The GFP( + ) neuron (green trace) is activated by cold, TAC, and menthol. A GFP( - neuron (red trace) is not activated by cold or menthol but shows a small response to TAC; typically, these neurons are activated by capsaicin. $\boldsymbol{B}$, Venn diagram summarizing the responses to TAC in GFP(+) and GFP( - ) neurons in Trpm $8^{\text {EGFPF/+ }}$ mice. C, Representative traces of fura-2 ratio fluorescence in cultured DRG neurons from a Trpm $8 \mathrm{KO}$ mouse. Same protocol as in $A$. Note the inhibition of the small TAC response by cooling in a GFP( - ) neuron (pink trace). A GFP $(+)$ neuron (green trace) does not respond to cold or menthol but responds to capsaicin. $\boldsymbol{D}$, Venn diagram summarizing the responses to TAC in GFP( + ) and GFP( - ) neurons in Trpm $8 \mathrm{KO}$ mice. $\boldsymbol{E}$, Summary of responses (in percentage of total neurons) to cold, TAC, and TAC plus cold in Trpm $8^{\text {BAC }}$-EYFP, Trpm $8^{\text {EGFPf/ }+}$, and Trpm $8^{\text {EGFPF/EGFP }}$ mice. For each mouse line, neurons have been separated as fluorescent or nonfluorescent. $\boldsymbol{F}$, Mean amplitude of TAC responses in fluorescent (TRPM8 ${ }^{\text {BAC }}$-EYFP and Trpm $8^{\text {EGFPF/+ }}$ ) and nonfluorescent neurons $\left(T r p m 8^{\text {EGFPf/+ }}\right.$ and Trpm $8^{\text {EGFPF/EFPF }}$. Differences in amplitude between fluorescent and nonfluorescent neurons were statistically significant (one-way ANOVA). ${ }^{*} p<0.05,{ }^{* *} p<0.01$.

(Dhaka et al., 2007). We compared responses in cultures from $\operatorname{Trpm} 8^{E G F P f /+}$ mice, which maintain one copy of TRPM8, with those in Trpm $8^{\text {EGFPf/EGFPf }}$ animals, thus null for TRPM8.

In Trpm $8^{\text {EGFPf/+ }}$ DRG cultures, $13 \%$ (67 of 515) of the neurons were fluorescent and practically all of them (66 of 67) were activated by cold or menthol, consistent with their expression of TRPM8 (Fig. 9A). Moreover, approximately half of the green fluorescent neurons were activated by TAC (35 of 67). In the presence of TAC, or menthol, cold responses were potentiated (Fig. 9A, green trace), consistent with an effect on TRPM8. The phenotype of $\mathrm{GFP}(-)$ neurons was very different: very few (2.4\%) were cold-sensitive, and only $2.7 \%$ (12 of 448 ) were activated by TAC (Fig. 9A, red trace), a significantly lower percentage $(p<0.001, Z$ test). A Venn diagram of these results is shown in Figure $9 B$. In summary, in agreement with the results observed in $\operatorname{Trpm} 8^{\mathrm{BAC}}$-EYFP mice, there is a high correlation between expression of TRPM8 and responses to TAC.

The responses to TAC in $\operatorname{Trp} m 8^{\text {EGFPf/EGFPf }}$ (i.e., $\operatorname{Trpm} 8 \mathrm{KO}$ ) mice were very infrequent, albeit detectable in some neurons
(Fig. 9C, pink trace). In total, only 13 of 516 (2.9\%) DRG neurons responded to $30 \mu \mathrm{M}$ TAC in Trpm $8 \mathrm{KO}$ animals ( 4 were $\mathrm{GFP}(+$ ) and 9 were $\operatorname{GFP}(-))$. The main reduction occurred in $\operatorname{GFP}(+)$ neurons, in parallel with a near suppression of their responses to cold or menthol (Fig. 9C, green trace). As summarized in Figure $9 D$, of $70 \mathrm{GFP}(+)$ neurons tested, only $4(5.7 \%)$ responded to TAC, a drastic reduction from the responses observed in $\mathrm{GFP}(+)$ neurons in $\operatorname{Trp} m 8^{E G F P f /+}$ mice $(p<0.001, Z$ test). Figure $9 E$ summarizes the responses to TAC and cold in fluorescent and nonfluorescent cells of the two transgenic mouse lines. It is evident that expression of TRPM8 is highly correlated with responses to TAC.

Finally, in GFP(-) neurons of Trpm $8^{\text {EGFPf/EGFPf }}$ mice, only $2 \%$ ( 9 of 446) responded to TAC, a very similar percentage to that observed in GFP $(-)$ neurons of $\operatorname{Trpm} 8^{\text {EGFPf/+ }}$ mice. The responses to TAC in GFP $(-)$ neurons had some distinct characteristics: because the results were similar in $\operatorname{Trpm} 8^{\text {EGFPfl+ }}$ and $\operatorname{Trpm} 8^{E G F P f / E G F P f}$ animals, we pooled them together. $\operatorname{In} \operatorname{GFP}(-)$ neurons, the amplitude of TAC responses was smaller $(p<$ 
A

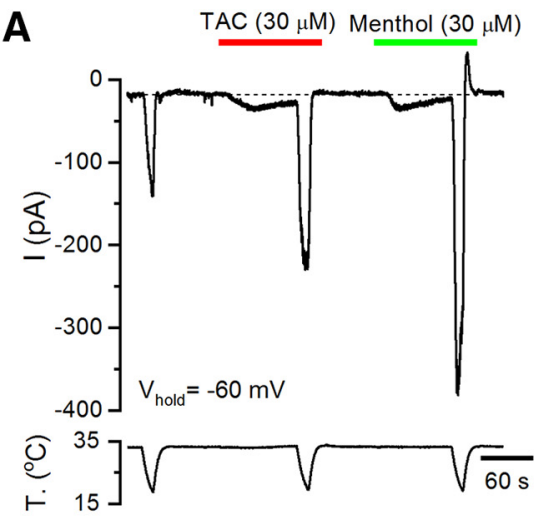

D

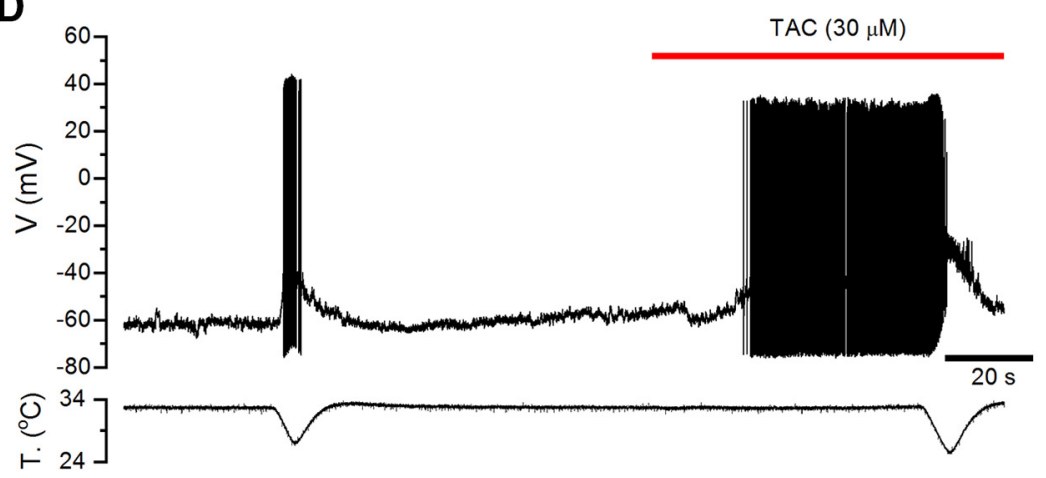

C
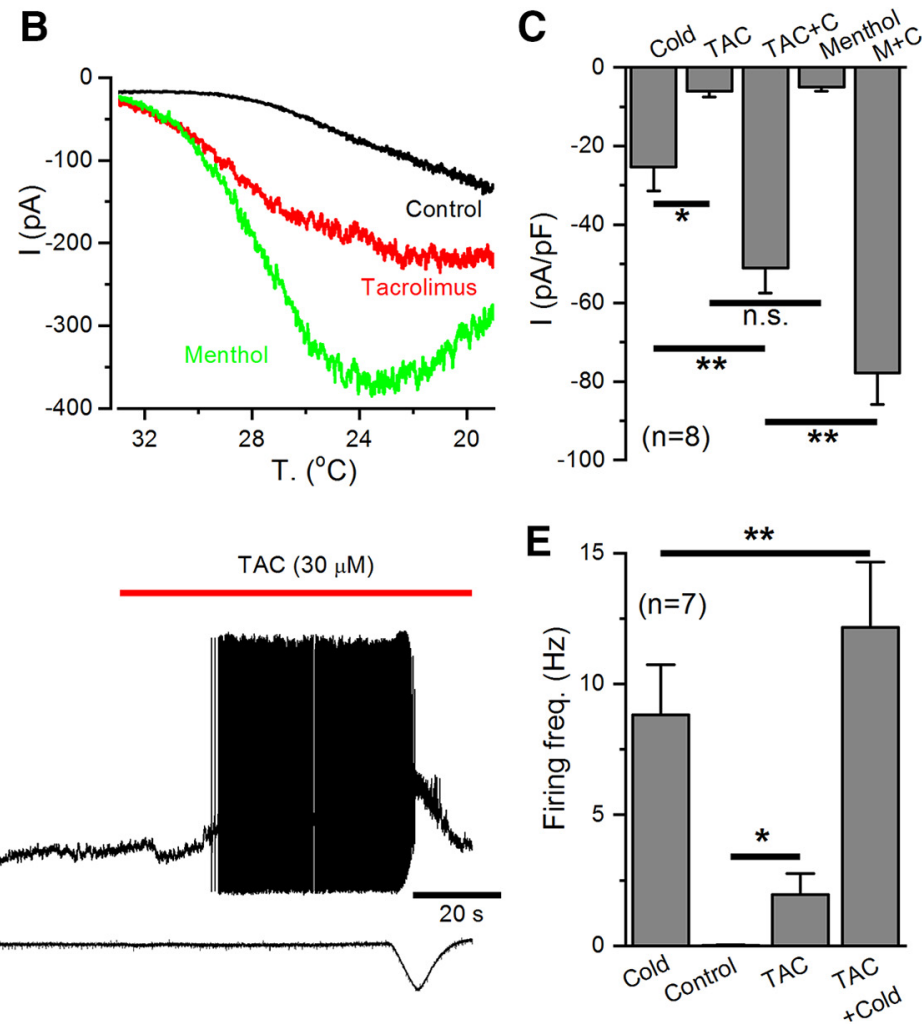

Figure 10. TAC increases the excitability of cold-sensitive DRG neurons. $A$, Representative whole-cell recording in the voltage-clamp configuration $\left(V_{\text {hold }}=-60 \mathrm{mV}\right)$ of a TRPM8-expressing, cold-sensitive DRG neuron identified by the expression of EYFP. TAC ( $30 \mu \mathrm{m})$ evoked an inward current similar in amplitude to that elicited by menthol (30 $\mu \mathrm{m})$. Both TAC and menthol strongly potentiate the response to cold. Bottom, Simultaneous recording of bath temperature during the recording. $\boldsymbol{B}$, Current-temperature relationships for the same neuron in control (black trace) and in the presence of $30 \mu \mathrm{m} \mathrm{TAC} \mathrm{(red} \mathrm{trace)} \mathrm{or} 30 \mu \mathrm{m}$ menthol (green trace). Note the marked shift in temperature threshold. C, Bar histogram summarizing the effects of agonists on the amplitude of inward currents during the protocol shown in $\boldsymbol{A}$. The statistical analysis consisted of a one-way ANOVA followed by Bonferroni's post hoc test $\left({ }^{*} p<0.05,{ }^{*} p<0.01\right)$. D, Representative recording of a cold-sensitive DRG neuron in the whole-cell current-clamp configuration showing responses to cold and to the application of TAC ( $30 \mu \mathrm{M})$. TAC evoked AP firing at $33^{\circ} \mathrm{C}$ and greatly enhanced the firing frequency during a cold ramp. Bottom, Simultaneous recording of bath temperature. $\boldsymbol{E}$, Bar histogram summarizing the mean responses, measured as average firing frequency, during the different stimuli applied. Firing frequency for cold was averaged from the first to the last spike during the cooling ramp. Firing frequency in control condition was calculated during the minute preceding TAC application (only 3 of 7 neurons fired action potentials in control conditions). TAC-evoked firing was calculated from the first spike during TAC application to the start of the cold ramp. The analysis consisted of a paired $t$ test for cold versus TAC plus cold ( $\left.{ }^{* *} p=0.009\right)$ and control vs TAC $\left({ }^{*} p=0.048\right.$ ).

0.001) compared with responses in fluorescent neurons of $\operatorname{Trpm} 8^{E G F P f /+}$ mice or $\operatorname{Trpm} 8^{\mathrm{BAC}}$-EYFP mice (Fig. 9F), and they were nearly abolished during the cooling ramp (Fig. 9A, C). None of these neurons was cold-sensitive (Fig. 9A, red trace). Interestingly, of the $21 \mathrm{GFP}(-)$ neurons activated by TAC, 18 also responded to capsaicin (100 nM) and 11 responded to AITC (50 $\mu \mathrm{M})$. These characteristics are consistent with a possible effect of TAC on TRPV1. However, we note that in these cultures $43.8 \%$ (452 of 1031) of the neurons responded to capsaicin, but only 22 of these $452(4.9 \%)$ responded to TAC.

Together, the results obtained with pharmacological blockers and after genetic inactivation of TRPM8 indicate that the main excitatory action of TAC in DRG neurons is mediated by activation of TRPM8 channels in cold-sensitive neurons, with some weaker effects on capsaicin-sensitive neurons, presumably though TRPV1.

\section{TAC activates inward currents and elicit AP firing in cold thermoreceptors}

The effect of TAC on the excitability of cold thermoreceptors was further evaluated by performing electrophysiological recordings in cultured DRG neurons from $\operatorname{Trpm} 8^{\mathrm{BAC}}$-EYFP mice. As shown in Figure $10 A$, in whole-cell patch-clamp recordings, TAC (30 $\mu \mathrm{M})$ activated an inward current and potentiated the currents evoked by cold temperature in all the $\operatorname{YFP}(+)$ neurons tested.
This potentiation was accompanied by a clear shift in the activation of cold-evoked currents to warmer temperatures (Fig. 10B). In the same neurons, application of menthol $(30 \mu \mathrm{M})$ produced similar effects to TAC, although its potentiating effect on coldevoked currents was stronger. A summary of these results is shown in Figure 10C.

Recordings in the current-clamp configuration of TRPM8expressing cold thermoreceptors, at a holding temperature of $33^{\circ} \mathrm{C}$, showed that TAC application induced the firing of action potentials and strongly potentiated cold-evoked firing (Fig. 10D). These results are summarized in Figure 10E.

These data confirm that TAC activates a depolarizing inward current similar to the TRPM8-dependent $\mathrm{I}_{\text {Cold }}$ current, increasing the excitability of cold-sensitive neurons.

\section{TAC activates cold-sensitive corneal afferents}

The corneal surface is densely innervated by cold-sensitive nerve endings that express TRPM8 channels (Parra et al., 2010; Alamri et al., 2018; Alcalde et al., 2018). We used extracellular recordings of these terminals in a mouse in vitro preparation to investigate the effects of TAC on sensory nerve endings.

Corneal cold-sensitive nerve endings are characterized by their spontaneous, low-frequency, background activity at $34^{\circ} \mathrm{C}$ with a sharp increase in firing rate, often organized in the form of bursts, during cooling (Fig. 11 A, C) (Carr et al., 2003; Parra et al., 
A

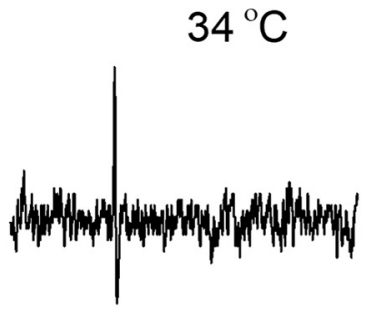

B

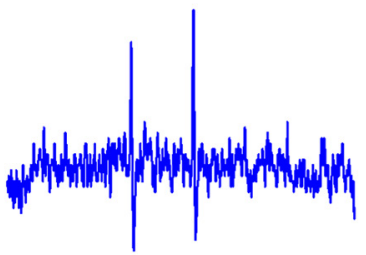

C

$34^{\circ} \mathrm{C}$
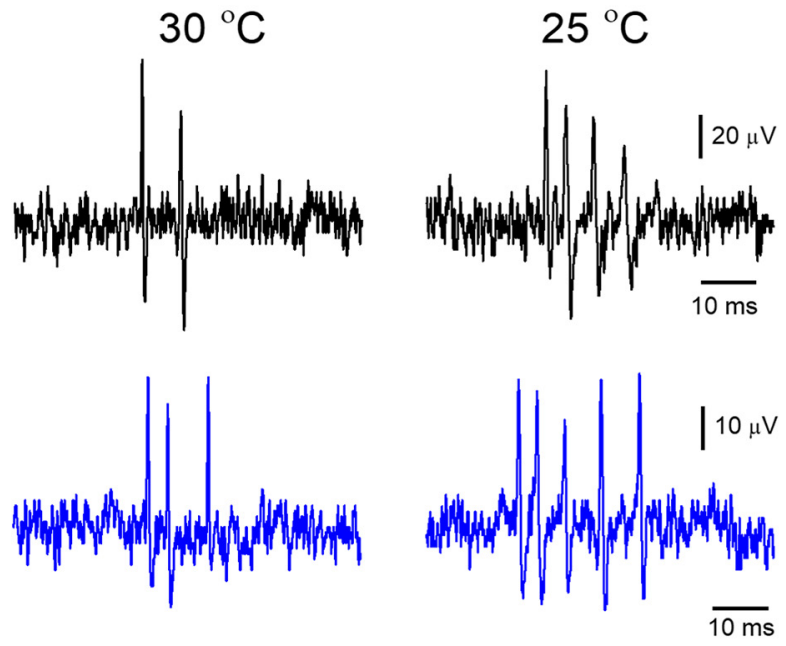

$30^{\circ} \mathrm{C}$

$25^{\circ} \mathrm{C}$

control
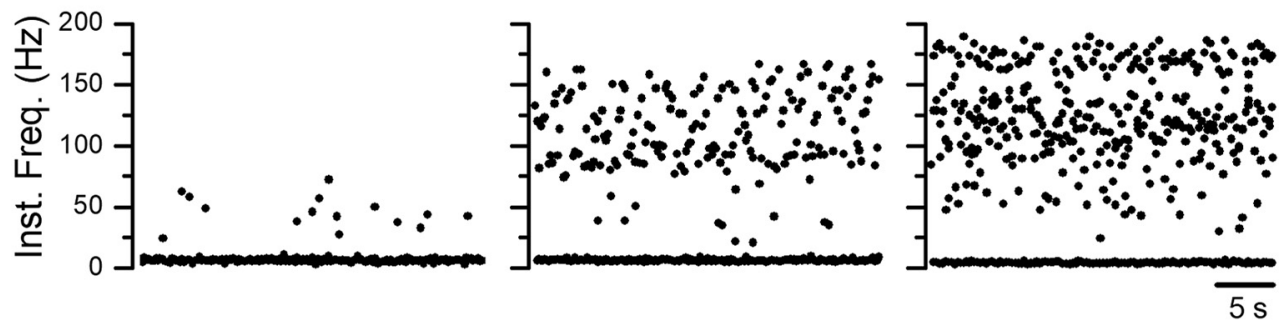

D

Tacrolimus
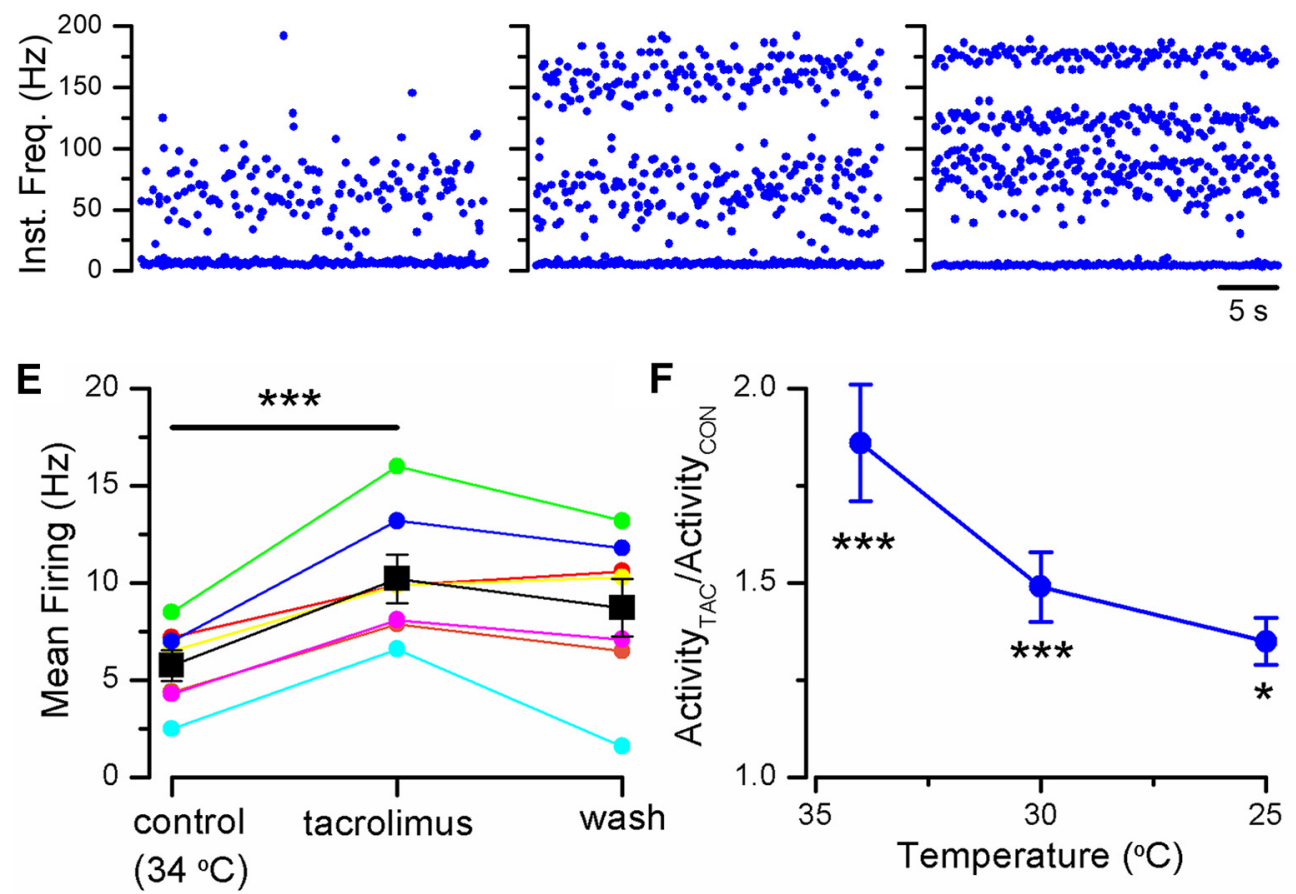

Figure 11. TAC activates corneal cold thermoreceptor endings. $A$, Representative example of nerve terminal impulses recorded from a mouse corneal ending in control solution, at three different temperatures. $\boldsymbol{B}$, Recordings from the same ending during application of $30 \mu \mathrm{M} \mathrm{TAC}$. C, Instantaneous firing frequency from the same ending as in $\boldsymbol{A}$ (control solution), and $\boldsymbol{D}$, as in $\boldsymbol{B}$ (in TAC). Note the regular firing in bursts during cooling. $E$, Summary of the effects of $30 \mu \mathrm{m}$ TAC on spontaneous firing in 7 individual endings at the basal temperature of $34^{\circ} \mathrm{C}$. The increase in firing was statistically significant $\left({ }^{* * *} p<0.001\right.$, paired Student's $t$ test). $\boldsymbol{F}$, Mean firing rate in TAC at three different temperatures in 7 cold thermoreceptor endings. Activity at each temperature has been normalized to the value obtained in control solution. Statistical differences evaluated by one-way ANOVA for repeated measures followed by Bonferroni post hoc test. $\left({ }^{*} p<0.05,{ }^{* * *} p<0.001\right.$.) 
2010; Orio et al., 2012). At a baseline temperature of $34^{\circ} \mathrm{C}$, exposure to $30 \mu \mathrm{M}$ TAC produced clear excitatory effects (Fig. $11 B, D$, left), with an increase in the basal firing rate, from $5.8 \pm 0.8 \mathrm{~Hz}$ in control to $10.2 \pm 1.6 \mathrm{~Hz}$ in TAC $(n=7, p<0.001$; paired Student's $t$ test). The firing rate increases during cooling in the presence of TAC (Fig. $11 B-D$, middle, right). Figure $11 E$ shows a summary of the effects of TAC on basal firing rate for individual cold-sensitive endings at $34^{\circ} \mathrm{C}$. The excitatory effect of TAC was also evident on the steady-state firing rate at lower temperatures, with an elevation in mean firing frequency and the increase in the number of spikes per burst (Fig. 11B). The potentiation of activity mediated by TAC at the different temperatures is shown in Figure $11 F$. The washout of TAC effects was only partial, probably explained by the long application times required to examine the effects of TAC at different temperatures and the lipophilic nature of the compound (Fig. 11E).

These results show that the excitatory effects of TAC on cold thermoreceptor activity are maintained at peripheral nerve endings, the physiological site for chemotransduction and thermotransduction in these neurons.

\section{TAC sensitizes cutaneous cold thermoreceptors}

To further characterize the effects of TAC on cold thermoreceptor endings, we used a mouse skin-nerve preparation. We focused our efforts on unimodal cutaneous cold receptors (i.e., coldactivated fibers insensitive to mechanical stimuli) because it is well known that TRPM8 plays an essential role in their coldevoked activity (Toro et al., 2015; Winter et al., 2017). We identified 9 fibers in the saphenous nerve with the aforesaid characteristics. These fibers were silent at the baseline temperature of $34^{\circ} \mathrm{C}-35^{\circ} \mathrm{C}$ but were activated when cold solution was delivered to their isolated receptive field (Fig. 12A,B), with a mean cold threshold of $30.4 \pm 1^{\circ} \mathrm{C}(n=9)$ (Fig. 12C). During application of TAC $(30 \mu \mathrm{M})$, none of the fibers presented activity at the basal temperature of $34^{\circ} \mathrm{C}$. However, their cold-evoked activity was clearly modified in the presence of TAC (Fig. 12 A,B). In 6 of these 9 fibers, TAC shifted their cold threshold to warmer temperatures (mean temperature threshold displacement of $2.1 \pm 0.5^{\circ} \mathrm{C}, n=9$ ) and shifted their stimulus response function to warmer temperatures (Fig. 12C). As in the cornea, the washout of TAC effects was only partial (Fig. $12 \mathrm{~B}, \mathrm{C}$ ). In these endings, menthol $(50 \mu \mathrm{M})$ produced qualitatively similar excitatory effects, although more intense. Thus, menthol produced an increase in spontaneous activity at the basal temperature of $34^{\circ} \mathrm{C}-35^{\circ} \mathrm{C}$ in 5 of 9 endings tested (Fig. $12 \mathrm{~B}$ ). In addition, menthol shifted their temperature threshold, by at least $1^{\circ} \mathrm{C}$, to warmer values in all of them $(n=9)$. The mean temperature threshold displacement produced by menthol was $3.3 \pm 0.7^{\circ} \mathrm{C}$ (Fig. 12C), and their overall firing was more pronounced and shifted to warmer temperatures (Fig. 12D). Collectively, these results indicate that TAC sensitizes a population of cutaneous TRPM8-expressing thermoreceptor endings to cold temperature.

\section{TAC evokes TRPM8-dependent cold hypersensitivity}

Agonists of TRPM8 channels can lead to cold-evoked avoidance behaviors (Rossi et al., 2006; Klein et al., 2010). Thus, we examined the possible influence of TAC on cold-evoked behaviors in mice. In adult WT mice, intraplantar injection of 1\% TAC decreased the latency of paw withdrawal from a cold plate set at $10^{\circ} \mathrm{C}$. The reduction was significant $(p<0.01$, one-way ANOVA) compared with the injection of vehicle or the latency observed in naive paws (Fig. 13A, left). Injection of $1 \%$ menthol, the canonical agonist of TRPM8 channels, also caused a significant reduction in withdrawal latency (Fig. 13A). To test for the role of TRPM8 in the cold hypersensitivity produced by TAC, we examined the withdrawal latency in $\operatorname{Tr} p m 8 \mathrm{KO}$ mice. As shown in Figure $13 \mathrm{~A}$ (right), in these mice, TAC failed to sensitize their response to cold (one-way ANOVA), and their withdrawal latency was significantly longer compared with results obtained in WT ( $p<0.01$, unpaired $t$ test).

These results confirm the role of TRPM8 channels in the cold hypersensitivity produced by TAC at peripheral nerve endings.

\section{TAC triggers tearing and blinking}

Afferent discharge from different classes of corneal sensory fibers, including cold receptors and polymodal nociceptors, participates in the neural mechanisms of basal and reflex-evoked tearing (Belmonte and Gallar, 2011; Meng and Kurose, 2013). We examined the effect of TAC solutions on tearing in anesthetized WT mice. We applied, sequentially, a small drop of saline, vehicle, or TAC (1\%) to both eyes and measured the tearing after a rest period of 5 min. As shown in Figure 13B, TAC produced a significant increase in tearing compared with saline $(p<0.01)$ or vehicle $(p<$ 0.05; one-way ANOVA). To control for possible sensitization effects produced by repeated applications of solutions to the corneal surface, we designed a control experiment, consisting of 3 consecutive applications of saline, which resulted in very similar mean values of tearing for each of them (Fig. 13C).

A previous study identified the critical role of TRPM8 channels in eye blinking in mice following application of hyperosmolar solutions (Quallo et al., 2015). Thus, we decided to investigate the effects of TAC solutions applied to the corneal surface. We counted the number of blinks observed after unilateral application of solutions with $1 \%$ TAC to the eyes of WT $(n=8)$ and $\operatorname{Trpm} 8^{-1-}$ mice $(n=17)$. Application of saline $(315 \mathrm{mOsm} / \mathrm{kg})$ or vehicle had only a small effect on blinking. In contrast, as shown in Figure 13D (left), 1\% TAC triggered a large increase in the number of blinks in WT mice. In agreement with previous findings (Quallo et al., 2015), hyperosmotic solutions (785 $\mathrm{mOsm} / \mathrm{kg}$ ) also triggered a marked increase in eye blinking, similar to that observed with TAC.

Repeating the tests in Trpm $8 \mathrm{KO}$ mice confirmed a reduction in blinking, compared with WT ( $p<0.01$, unpaired $t$ test), produced by hyperosmolar solutions reported previously. In contrast, the blinks produced by $1 \% \mathrm{TAC}$ in Trpm $8 \mathrm{KO}$ mice were very variable, but they were not different from those observed in WT mice (Fig. $13 D$, right). These results suggest that $1 \%$ TAC has effects on blinking that are in independent of TRPM8 activity.

\section{Discussion}

Natural products remain an important source for the development of pharmaceutical drugs (Newman and Cragg, 2016), and have also played a fundamental role in the discovery and characterization of TRP channels (Julius, 2005; Nilius and Appendino, 2011; Meotti et al., 2014). However, despite major drug discovery efforts, the number of chemical agonists reported for TRPM8 channels is still very modest (Bödding et al., 2007; Almaraz et al., 2014; LeGay et al., 2016; Moran and Szallasi, 2018). Moreover, many of these agonists show cross-sensitivity with other TRP channels (Macpherson et al., 2006). We have identified TAC, a clinically relevant macrolide immunosuppressant produced by soil microorganisms, as a novel agonist of TRPM8 channels. These findings highlight a novel neuroimmune interface in peripheral tissues with several potential applications. First, it expands the current arsenal of drugs targeting TRPM8 and provides 

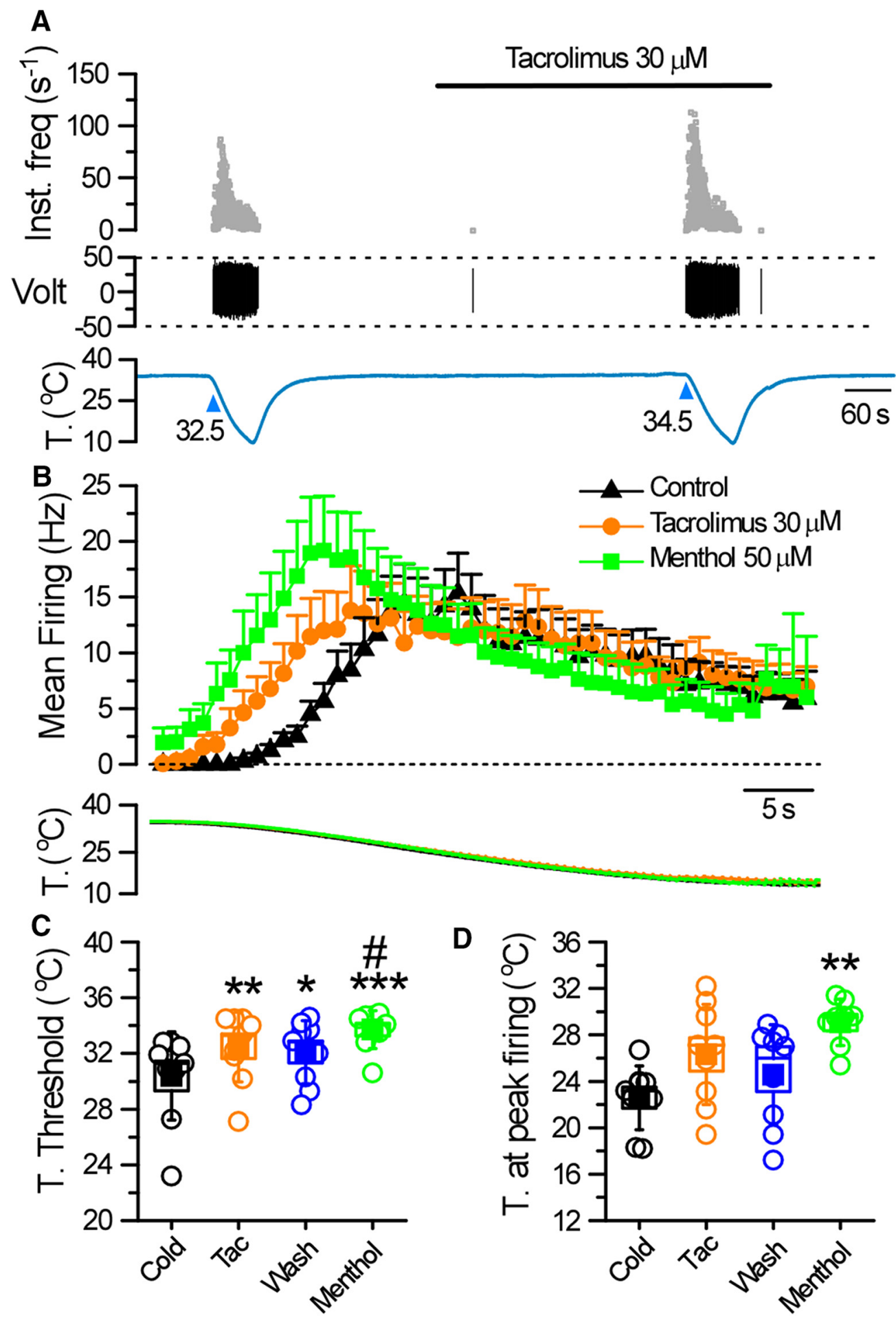

Figure 12. TAC activates cutaneous cold thermoreceptors. $A$, Representative recording showing the response of a cold fiber to a decrease in the temperature of the isolated receptive field, before and after treatment with $30 \mu \mathrm{M} \mathrm{TAC}$. Top to bottom, Instantaneous firing frequency, the voltage signal, and the temperature of the receptive field. $\boldsymbol{B}$, Histogram showing the averaged cold-evoked response of cold fibers from C57BL/6J mice in control solution (black triangles), in the presence of $30 \mu \mathrm{m} \mathrm{TAC} \mathrm{(orange} \mathrm{circles),} \mathrm{and} \mathrm{in} 50 \mu \mathrm{m} \mathrm{menthol} \mathrm{(green} \mathrm{squares).} \mathrm{Average} \mathrm{discharge} \mathrm{rates} \mathrm{are}$ represented in bins of $2 \mathrm{~s}$. Bottom, The temperature ramp for each of the datasets. $\boldsymbol{C}$, Temperature threshold for activation of impulse discharge. $\boldsymbol{D}$, Temperature for reaching the maximal discharge rate. Squares represent mean values. Boxes represent SEM. Error bars indicate standard deviation (SD). In $C$ and $\boldsymbol{D},{ }^{*} p<0.05,{ }^{* *} p<0.01,{ }^{* * *} p<0.001$ (one-way ANOVA with Bonferroni's post hoc correction). The asterisks compare significance with respect to cold. The ${ }^{\#}(p<0.05)$ compares significance with respect to wash.

new clues about its activation mechanism. Second, the effects of TAC on TRPM8 could be used as an experimental tool to investigate the functional activity of this polymodal ion channel in humans, for example, as a new surrogate model of cold allodynia and hyperalgesia (Andersen et al., 2014).
In contrast to TAC, cyclosporine, a cyclic undecapeptide also targeting calcineurin signaling, had no effect on TRPM8 or coldevoked responses in DRG neurons. This result excludes this pathway as the one involved in the effects of TAC. Moreover, the activation of reconstituted TRPM8 by TAC in planar lipid bilay- 

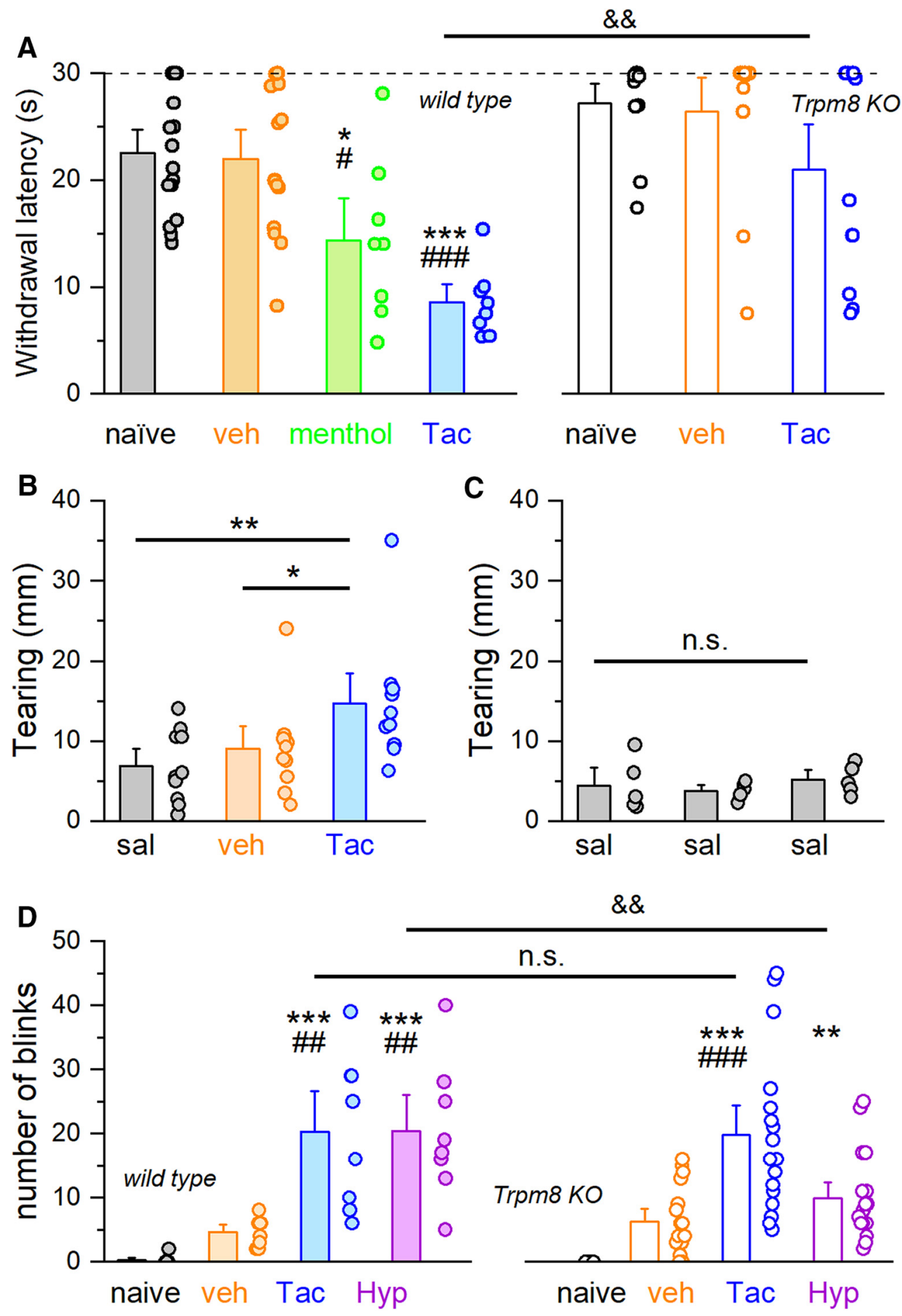

\&\&

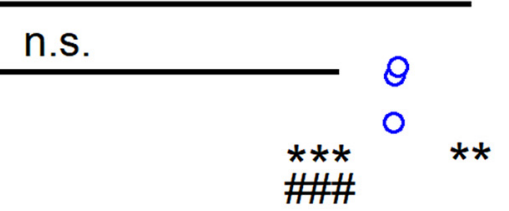


ers conclusively demonstrates that the interaction of TAC with the channel is direct and does not require signaling cascades. Similarly to the activation by cold and menthol, the gating of TRPM8 by TAC depended specifically on the presence of $\mathrm{PI}(4,5) \mathrm{P}_{2}$ (Zakharian et al., 2010).

\section{Biophysical and molecular aspects of TAC agonism on TRPM8}

In many aspects, the activation of TRPM8 by TAC resembles the effects of menthol on channel gating: TAC shifts the activation threshold of TRPM8 to higher temperatures and slows the activation kinetics. These characteristics fit with the description of Type I agonists introduced by Janssens et al. (2016), which include menthol, thymol, icilin, and linalool. Interestingly, the effects of TAC persisted in a menthol-insensitive mutant. Our previous characterization of antagonist effects on TRPM8 suggested a sequential model of TRPM8 gating where chemical modulators can favor (e.g., menthol) or hinder (e.g., BCTC or SKF96365) the energetics of subsequent channel opening by cold temperature or voltage from different binding sites (Mälkiä et al., 2009). This model is consistent with the actions of TAC, having an excitatory action on the menthol-insensitive $\mathrm{Y} 745 \mathrm{H}$ mutant, but failing to facilitate the gating by cold temperature, suggesting that the actions of different chemical agonists converge from independent binding sites.

The identification of the residues critical for TAC effects should be addressed in the future; we excluded its interaction with the icilin and menthol binding sites. The recent cryostructure of the TRPM8 tetramer could facilitate their identification (Yin et al., 2018).

\section{Specificity of TAC effects}

Based on the pharmacological characterization in WT, hemizygous, and Trpm 8 null mice, we conclude that the effects of TAC on TRPM8-expressing sensory neurons is highly selective. However, this specificity is not absolute. In cultured neurons of Trpm8 $\mathrm{KO}$ mice, a small effect of TAC remains that is likely mediated by TRPV1. A previous study found that TAC activated a small percentage $(3.1 \%)$ of rat DRG neurons, and many of these neurons were also activated by capsaicin (Senba et al., 2004). As in our case, and consistent with a weak effect, the percentage of capsaicin-positive neurons was much higher than those responding to TAC. Surprisingly, we did not observe any effects of TAC on recombinant TRPV 1 channels. In contrast, TAC also activated TRPA1 expressed heterologously, albeit less affectively than TRPM8.

The behavioral results indicate that the cold hypersensitivity produced by TAC is clearly mediated by TRPM8. The stronger effects of TAC compared with menthol, opposite to the effects observed in vitro, may be explained by its actions on other ion channels (Swandulla et al., 1987). Moreover, it is well known that high concentrations of topical menthol, as used here, are analgesic (Liu et al., 2013). A reported side effect of TAC treatment is the experience of chills. They could be caused by activation of TRPM8 because it is an effect observed with other TRPM8 agonists (e.g., icilin), and linked to the role of the channel in thermoregulation (Knowlton et al., 2011; Pogorzala et al., 2013; Reimúndez et al., 2018).

Topical applications of $1 \%$ TAC solutions also increased basal tearing and triggered eye blinking. However, in this last case, the effects were not reduced in TRPM8 KO mice. This result suggests that this solution has irritant effects that are independent of TRPM8 activation. Because topical TAC formulations have much higher concentrations of the drug than we could test in solution in vitro, it could lead to activation of other nociceptive TRP channels, explaining the transient burning sensation reported upon topical application of TAC to the eye (Fukushima et al., 2014; Abud et al., 2016) and the skin. These irritant actions are the most common side effect associated with topical application of TAC. Consistent with a possible activation of TRPA1, in a murine model of chronic contact hypersensitivity, TAC increased the number of scratch bouts, and these were significantly reduced by topical application of a TRPA1 antagonist (Wong et al., 2018). Alternatively, because a subpopulation of TRPM8expressing primary sensory neurons have a nociceptive phenotype (Xing et al., 2006; Alcalde et al., 2018), and many also express TRPV1, their activation may contribute to the transient discomfort produced by TAC.

\section{Therapeutic implications}

TRPM8 plays a multifaceted role in cold-related pain. On one hand, it appears to participate in the mechanisms of cold hyperalgesia and allodynia (Knowlton et al., 2013). At the same time, it is the principal mechanism of menthol-induced analgesia (Liu et al., 2013), and also plays a significant role in cooling-mediated analgesia (Proudfoot et al., 2006; Knowlton et al., 2013). Activation of TRPM8 sensory pathways also reliefs the sensation of itch (Palkar et al., 2018). Moreover, TRPM8 activation has a potent anti-inflammatory role in the gut (Ramachandran et al., 2013). Therefore, TRPM8 modulators (agonists and antagonists) may offer multiple possibilities in the relief of pain and visceral inflammation (Pérez de Vega et al., 2016; Moran and Szallasi, 2018).

Because activation of TRPM8 regulates basal tearing and blinking (Parra et al., 2010; Quallo et al., 2015), it has been proposed as a possible therapy for DED (Parra et al., 2010; Belmonte and Gallar, 2011). In addition to its use as a systemic immunosuppressant in the prevention of organ rejection, TAC is also used topically in the treatment of DED symptoms (Jones et al., 2017). In clinical ophthalmology, TAC has been used in solutions at concentrations up to $0.1 \%$. This is equivalent to $1.2 \mathrm{~mm}$, suggesting that it should readily activate TRPM8 channels at corneal endings. We observed a clear effect of $1 \%$ TAC solutions on basal tearing and eye blinking, suggesting that some of the beneficial effects reported for TAC in dry-eye conditions (Abud et al., 2016) may involve activation of TRPM8 channels in trigeminal cold thermoreceptor endings. However, the fact that blinking was not reduced in TRPM8 null mice clearly indicates that other mechanisms are involved at this concentration and with this particular formulation. The activation of TRPA1, and possibly TRPV1, at these high concentrations of TAC could also explain the burning sensation reported by some patients.

We also show that TAC activates cutaneous cold thermoreceptor endings and sensitizes responses to cold temperature. The apparent potency was lower than for corneal endings. This, however, may reflect a poor accessibility of the drug in the in vitro preparation we used, which lacks vascularization and requires application of substances through the corium. Whether activation of TRPM8 by TAC is relevant for the treatment of atopic dermatitis is currently unclear. Nevertheless, it is becoming well established that electrical activity in peripheral sensory endings can have potent immunomodulatory effects (Chavan et al., 2017), suggesting that modulation of TRPM8 channels by TAC may play a role in its anti-inflammatory actions. At this point, this is just a hypothesis but with important implications. 
In conclusion, we report the activation of cold-activated TRPM8 channels by the natural immunosuppressant TAC. The speed of the effect and the action on reconstituted channels make it incompatible with transcriptional actions. Biophysically, the effects of TAC on TRPM8 gating resemble those of menthol, although mutagenesis studies suggest and independent binding site.

\section{References}

Abud TB, Amparo F, Saboo US, Di Zazzo A, Dohlman TH, Ciolino JB, Hamrah P, Dana R (2016) A clinical trial comparing the safety and efficacy of topical tacrolimus versus methylprednisolone in ocular graft-versus-host disease. Ophthalmology 123:1449-1457. CrossRef Medline

Alamri AS, Wood RJ, Ivanusic JJ, Brock JA (2018) The neurochemistry and morphology of functionally identified corneal polymodal nociceptors and cold thermoreceptors. PLoS One 13:e0195108. CrossRef Medline

Alcalde I, Íñigo-Portugués A, González-González O, Almaraz L, Artime E, Morenilla-Palao C, Gallar J, Viana F, Merayo-Lloves J, Belmonte C (2018) Morphological and functional changes in TRPM8-expressing corneal cold thermoreceptor neurons during aging and their impact on tearing in mice. J Comp Neurol 526:1859-1874. CrossRef Medline

Almaraz L, Manenschijn JA, de la Peña E, Viana F (2014) Trpm8. Handb Exp Pharmacol 222:547-579. CrossRef Medline

Andersen HH, Olsen RV, Møller HG, Eskelund PW, Gazerani P, ArendtNielsen L (2014) A review of topical high-concentration L-menthol as a translational model of cold allodynia and hyperalgesia. Eur J Pain 18:315325. CrossRef Medline

Andrews MD, Af Forselles K, Beaumont K, Galan SR, Glossop PA, Grenie M, Jessiman A, Kenyon AS, Lunn G, Maw G, Owen RM, Pryde DC, Roberts D, Tran TD (2015) Discovery of a selective TRPM8 antagonist with clinical efficacy in cold-related pain. ACS Med Chem Lett 6:419-424. CrossRef Medline

Asuthkar S, Demirkhanyan L, Sun X, Elustondo PA, Krishnan V, Baskaran P, Velpula KK, Thyagarajan B, Pavlov EV, Zakharian E (2015) The TRPM8 protein is a testosterone receptor: II. Functional evidence for an ionotropic effect of testosterone on TRPM8. J Biol Chem 290:2670-2688. CrossRef Medline

Bandell M, Dubin AE, Petrus MJ, Orth A, Mathur J, Hwang SW, Patapoutian A (2006) High-throughput random mutagenesis screen reveals TRPM8 residues specifically required for activation by menthol. Nat Neurosci 9:493-500. CrossRef Medline

Bautista DM, Siemens J, Glazer JM, Tsuruda PR, Basbaum AI, Stucky CL, Jordt SE, Julius D (2007) The menthol receptor TRPM8 is the principal detector of environmental cold. Nature 448:204-208. CrossRef Medline

Beck LA (2005) The efficacy and safety of tacrolimus ointment: a clinical review. J Am Acad Dermatol 53:S165-S170. CrossRef Medline

Belmonte C, Gallar J (2011) Cold thermoreceptors, unexpected players in tear production and ocular dryness sensations. Invest Ophthalmol Vis Sci 52:3888-3892. CrossRef Medline

Belmonte C, Nichols JJ, Cox SM, Brock JA, Begley CG, Bereiter DA, Dartt DA, Galor A, Hamrah P, Ivanusic JJ, Jacobs DS, McNamara NA, Rosenblatt MI, Stapleton F, Wolffsohn JS (2017) TFOS DEWS II pain and sensation report. Ocul Surf 15:404-437. CrossRef Medline

Bidaux G, Borowiec AS, Gordienko D, Beck B, Shapovalov GG, Lemonnier L, Flourakis M, Vandenberghe M, Slomianny C, Dewailly E, Delcourt P, Desruelles E, Ritaine A, Polakowska R, Lesage J, Chami M, Skryma R, Prevarskaya N (2015) Epidermal TRPM8 channel isoform controls the balance between keratinocyte proliferation and differentiation in a colddependent manner. Proc Natl Acad Sci U S A 112:E3345-E3354. CrossRef Medline

Bödding M, Wissenbach U, Flockerzi V (2007) Characterisation of TRPM8 as a pharmacophore receptor. Cell Calcium 42:618-628. CrossRef Medline

Brauchi S, Orio P, Latorre R (2004) Clues to understanding cold sensation: thermodynamics and electrophysiological analysis of the cold receptor TRPM8. Proc Natl Acad Sci U S A 101:15494-15499. CrossRef Medline

Carr RW, Pianova S, Fernandez J, Fallon JB, Belmonte C, Brock JA (2003) Effects of heating and cooling on nerve terminal impulses recorded from cold-sensitive receptors in the guinea-pig cornea. J Gen Physiol 121:427439. CrossRef Medline

Chavan SS, Pavlov VA, Tracey KJ (2017) Mechanisms and therapeutic rel- evance of neuro-immune communication. Immunity 46:927-942. CrossRef Medline

Chuang HH, Neuhausser WM, Julius D (2004) The super-cooling agent icilin reveals a mechanism of coincidence detection by a temperaturesensitive TRP channel. Neuron. 43:859-869. CrossRef Medline

Dhaka A, Viswanath V, Patapoutian A (2006) Trp ion channels and temperature sensation. Annu Rev Neurosci 29:135-161. CrossRef Medline

Dhaka A, Murray AN, Mathur J, Earley TJ, Petrus MJ, Patapoutian A (2007) TRPM8 is required for cold sensation in mice. Neuron 54:371-378. CrossRef Medline

Dhaka A, Earley TJ, Watson J, Patapoutian A (2008) Visualizing cold spots: TRPM8-expressing sensory neurons and their projections. J Neurosci 28:566-575. CrossRef Medline

Fukushima A, Ohashi Y, Ebihara N, Uchio E, Okamoto S, Kumagai N, Shoji J, Takamura E, Nakagawa Y, Namba K, Fujishima H, Miyazaki D (2014) Therapeutic effects of $0.1 \%$ tacrolimus eye drops for refractory allergic ocular diseases with proliferative lesion or corneal involvement. Br J Ophthalmol 98:1023-1027. CrossRef Medline

González-González O, Bech F, Gallar J, Merayo-Lloves J, Belmonte C (2017) Functional Properties of Sensory Nerve Terminals of the Mouse Cornea. Invest Ophthalmol Vis Sci. 58:404-415. CrossRef

Janssens A, Gees M, Toth BI, Ghosh D, Mulier M, Vennekens R, Vriens J, Talavera K, Voets T (2016) Definition of two agonist types at the mammalian cold-activated channel TRPM8. Elife 5:e17240. CrossRef Medline

Jones L, Downie LE, Korb D, Benitez-Del-Castillo JM, Dana R, Deng SX, Dong PN, Geerling G, Hida RY, Liu Y, Seo KY, Tauber J, Wakamatsu TH, Xu J, Wolffsohn JS, Craig JP (2017) TFOS DEWS II management and therapy report. Ocul Surf 15:575-628. CrossRef Medline

Julius D (2005) From peppers to peppermints: natural products as probes of the pain pathway. Harvey Lect 101:89-115. Medline

Klein AH, Sawyer CM, Carstens MI, Tsagareli MG, Tsiklauri N, Carstens E (2010) Topical application of L-menthol induces heat analgesia, mechanical allodynia, and a biphasic effect on cold sensitivity in rats. Behav Brain Res 212:179-186. CrossRef Medline

Knowlton WM, Daniels RL, Palkar R, McCoy DD, McKemy DD (2011) Pharmacological blockade of TRPM8 ion channels alters cold and cold pain responses in mice. PLoS One 6:e25894. CrossRef Medline

Knowlton WM, Palkar R, Lippoldt EK, McCoy DD, Baluch F, Chen J, McKemy DD (2013) A sensory-labeled line for cold: TRPM8-expressing sensory neurons define the cellular basis for cold, cold pain, and coolingmediated analgesia. J Neurosci 33:2837-2848. CrossRef Medline

LeGay CM, Gorobets E, Iftinca M, Ramachandran R, Altier C, Derksen DJ (2016) Natural-product-derived transient receptor potential melastatin 8 (TRPM8) channel modulators. Org Lett 18:2746-2749. CrossRef Medline

Liu B, Qin F (2005) Functional control of cold- and menthol-sensitive TRPM8 ion channels by phosphatidylinositol 4,5-bisphosphate. J Neurosci 25:1674-1681. CrossRef Medline

Liu B, Fan L, Balakrishna S, Sui A, Morris JB, Jordt SE (2013) TRPM8 is the principal mediator of menthol-induced analgesia of acute and inflammatory pain. Pain 154:2169-2177. CrossRef Medline

Macpherson LJ, Hwang SW, Miyamoto T, Dubin AE, Patapoutian A, Story GM (2006) More than cool: promiscuous relationships of menthol and other sensory compounds. Mol Cell Neurosci 32:335-343. CrossRef Medline

Mälkiä A, Madrid R, Meseguer V, de la Peña E, Valero M, Belmonte C, Viana F (2007) Bidirectional shifts of TRPM8 channel gating by temperature and chemical agents modulate the cold sensitivity of mammalian thermoreceptors. J Physiol 581:155-174. CrossRef Medline

Mälkiä A, Pertusa M, Fernández-Ballester G, Ferrer-Montiel A, Viana F (2009) Differential role of the menthol-binding residue Y745 in the antagonism of thermally gated TRPM8 channels. Mol Pain 5:62. CrossRef Medline

McKemy DD, Neuhausser WM, Julius D (2002) Identification of a cold receptor reveals a general role for TRP channels in thermosensation. Nature 416:52-58. CrossRef Medline

Menéndez L, Lastra A, Hidalgo A, Baamonde A (2002) Unilateral hot plate test: a simple and sensitive method for detecting central and peripheral hyperalgesia in mice. J Neurosci Methods 113:91-97. CrossRef Medline

Meng ID, Kurose M (2013) The role of corneal afferent neurons in regulating tears under normal and dry eye conditions. Exp Eye Res 117:79-87. CrossRef Medline 
Meotti FC, Lemos de Andrade E, Calixto JB (2014) TRP modulation by natural compounds. Handb Exp Pharmacol 223:1177-1238. CrossRef Medline

Moran MM, Szallasi A (2018) Targeting nociceptive transient receptor potential channels to treat chronic pain: current state of the field. Br J Pharmacol 175:2185-2203. CrossRef Medline

Morenilla-Palao C, Luis E, Fernández-Peña C, Quintero E, Weaver JL, Bayliss DA, Viana F (2014) Ion channel profile of TRPM8 cold receptors reveals a role of TASK-3 potassium channels in thermosensation. Cell Rep 8:1571-1582. CrossRef Medline

Newman DJ, Cragg GM (2016) Natural products as sources of new drugs from 1981 to 2014. J Nat Prod 79:629-661. CrossRef Medline

Nilius B, Appendino G (2011) Tasty and healthy TR(i)Ps: the human quest for culinary pungency. EMBO Rep 12:1094-1101. CrossRef Medline

Orio P, Parra A, Madrid R, González O, Belmonte C, Viana F (2012) Role of in in the firing pattern of mammalian cold thermoreceptor endings. J Neurophysiol 108:3009-3023. CrossRef Medline

Palkar R, Ongun S, Catich E, Li N, Borad N, Sarkisian A, McKemy DD (2018) Cooling relief of acute and chronic itch requires TRPM8 channels and neurons. J Invest Dermatol 138:1391-1399. CrossRef Medline

Parra A, Madrid R, Echevarria D, del Olmo S, Morenilla-Palao C, Acosta MC, Gallar J, Dhaka A, Viana F, Belmonte C (2010) Ocular surface wetness is regulated by TRPM8-dependent cold thermoreceptors of the cornea. Nat Med 16:1396-1399. CrossRef Medline

Peier AM, Moqrich A, Hergarden AC, Reeve AJ, Andersson DA, Story GM, Earley TJ, Dragoni I, McIntyre P, Bevan S, Patapoutian A (2002) A TRP channel that senses cold stimuli and menthol. Cell 108:705-715. CrossRef Medline

Pereira U, Boulais N, Lebonvallet N, Pennec JP, Dorange G, Misery L (2010) Mechanisms of the sensory effects of tacrolimus on the skin. Br J Dermatol 163:70-77. CrossRef Medline

Pérez de Vega MJ, Gómez-Monterrey I, Ferrer-Montiel A, González-MuñizR (2016) Transient receptor potential melastatin 8 channel (TRPM8) modulation: cool entryway for treating pain and cancer. J Med Chem 59:10006-10029. CrossRef Medline

Pogorzala LA, Mishra SK, Hoon MA (2013) The cellular code for mammalian thermosensation. J Neurosci 33:5533-5541. CrossRef Medline

Proudfoot CJ, Garry EM, Cottrell DF, Rosie R, Anderson H, Robertson DC, Fleetwood-Walker SM, Mitchell R (2006) Analgesia mediated by the TRPM8 cold receptor in chronic neuropathic pain. Curr Biol 16:15911605. CrossRef Medline

Quallo T, Vastani N, Horridge E, Gentry C, Parra A, Moss S, Viana F, Belmonte C, Andersson DA, Bevan S (2015) TRPM8 is a neuronal osmosensor that regulates eye blinking in mice. Nat Commun 6:7150. CrossRef Medline

Ramachandran R, Hyun E, Zhao L, Lapointe TK, Chapman K, Hirota CL, Ghosh S, McKemy DD, Vergnolle N, Beck PL, Altier C, Hollenberg MD (2013) TRPM8 activation attenuates inflammatory responses in mouse models of colitis. Proc Natl Acad Sci U S A 110:7476-7481. CrossRef Medline

Reid G, Amuzescu B, Zech E, Flonta ML (2001) A system for applying rapid warming or cooling stimuli to cells during patch clamp recording or ion imaging. J Neurosci Methods 111:1-8. CrossRef Medline

Reimúndez A, Fernández-Peña C, García G, Fernández R, Ordás P, Gallego R, Pardo-Vazquez JL, Arce V, Viana F, Señarís R (2018) Deletion of the cold thermoreceptor TRPM8 increases heat loss and food intake leading to reduced body temperature and obesity in mice. J Neurosci 38:36433656. CrossRef Medline

Robbins A, Kurose M, Winterson BJ, Meng ID (2012) Menthol activation of corneal cool cells induces TRPM8-mediated lacrimation but not nocice- ptive responses in rodents. Invest Ophthalmol Vis Sci 53:7034-7042. CrossRef Medline

Rohács T, Lopes CM, Michailidis I, Logothetis DE (2005) PI(4,5)P2 regulates the activation and desensitization of TRPM8 channels through the TRP domain. Nat Neurosci 8:626-634. CrossRef Medline

Rossi HL, Vierck CJ Jr, Caudle RM, Neubert JK (2006) Characterization of cold sensitivity and thermal preference using an operant orofacial assay. Mol Pain 2:37. CrossRef Medline

Roza C, Belmonte C, Viana F (2006) Cold sensitivity in axotomized fibers of experimental neuromas in mice. Pain 120:24-35. CrossRef Medline

Rusnak F, Mertz P (2000) Calcineurin: form and function. Physiol Rev 80: 1483-1521. CrossRef Medline

Senba E, Katanosaka K, Yajima H, Mizumura K (2004) The immunosuppressant FK506 activates capsaicin- and bradykinin-sensitive DRG neurons and cutaneous C-fibers. Neurosci Res 50:257-262. CrossRef Medline

Ständer S, Augustin M, Roggenkamp D, Blome C, Heitkemper T, Worthmann AC, Neufang G (2017) Novel TRPM8 agonist cooling compound against chronic itch: results from a randomized, double-blind, controlled, pilot study in dry skin. J Eur Acad Dermatol Venereol 31:1064-1068. CrossRef Medline

Stull C, Lavery MJ, Yosipovitch G (2016) Advances in therapeutic strategies for the treatment of pruritus. Expert Opin Pharmacother 17:671-687. CrossRef Medline

Swandulla D, Carbone E, Schäfer K, Lux HD (1987) Effect of menthol on two types of $\mathrm{Ca}$ currents in cultured sensory neurons of vertebrates. Pflugers Arch 409:52-59. CrossRef Medline

Takashima Y, Daniels RL, Knowlton W, Teng J, Liman ER, McKemy DD (2007) Diversity in the neural circuitry of cold sensing revealed by genetic axonal labeling of transient receptor potential melastatin 8 neurons. J Neurosci 27:14147-14157. CrossRef Medline

Toro CA, Eger S, Veliz L, Sotelo-Hitschfeld P, Cabezas D, Castro MA, Zimmermann K, Brauchi S (2015) Agonist-dependent modulation of cell surface expression of the cold receptor TRPM8. J Neurosci 35:571-582. CrossRef Medline

Voets T, Droogmans G, Wissenbach U, Janssens A, Flockerzi V, Nilius B (2004) The principle of temperature-dependent gating in cold- and heatsensitive TRP channels. Nature 430:748-754. CrossRef Medline

Wan XC, Dimov V (2014) Pharmacokinetic evaluation of topical calcineurin inhibitors for treatment of allergic conjunctivitis. Expert Opin Drug Metab Toxicol 10:543-549. CrossRef Medline

Winter Z, Gruschwitz P, Eger S, Touska F, Zimmermann K (2017) Cold temperature encoding by cutaneous TRPA1 and TRPM8-carrying fibers in the mouse. Front Mol Neurosci 10:209. CrossRef Medline

Wong LS, Otsuka A, Yamamoto Y, Nonomura Y, Nakashima C, Kitayama N, Usui K, Honda T, Kabashima K (2018) TRPAl channel participates in tacrolimus-induced pruritus in a chronic contact hypersensitivity murine model. J Dermatol Sci 89:207-209. CrossRef Medline

Xing H, Ling J, Chen M, Gu JG (2006) Chemical and cold sensitivity of two distinct populations of TRPM8-expressing somatosensory neurons. J Neurophysiol 95:1221-1230. CrossRef Medline

Yin Y, Wu M, Zubcevic L, Borschel WF, Lander GC, Lee SY (2018) Structure of the cold- and menthol-sensing ion channel TRPM8. Science 359:237241. CrossRef Medline

Zakharian E, Cao C, Rohács T (2010) Gating of transient receptor potential melastatin 8 (TRPM8) channels activated by cold and chemical agonists in planar lipid bilayers. J Neurosci 30:12526-12534. CrossRef Medline

Zimmermann K, Hein A, Hager U, Kaczmarek JS, Turnquist BP, Clapham DE, Reeh PW (2009) Phenotyping sensory nerve endings in vitro in the mouse. Nat Protoc 4:174-196. CrossRef Medline 